\begin{tabular}{|l|l|}
\hline Fronteras y seguridad en el nuevo regionalismo estratégico & Titulo \\
\hline Moncada Paredes, Martha - Autor/a; & Autor(es) \\
\hline Buenos Aires & Lugar \\
\hline CLACSO & Editorial/Editor \\
\hline 2016 & Fecha \\
\hline $\begin{array}{l}\text { Bienes comunes; Territorio; Seguridad; Regionalismo; Fronteras; América del Sur; } \\
\text { América Latina; }\end{array}$ & Colección \\
\hline Doc. de trabajo / Informes & Temas \\
\hline "http://biblioteca.clacso.edu.ar/lacso/becas/20160216080719/rronterasmm.pdf" & Tipo de documento \\
\hline $\begin{array}{l}\text { Reconocimiento-No Comercial-Sin Derivadas CC BY-NC-ND } \\
\text { http://creativecommons.org/licenses/by-nc-nd/2.0/deed.es }\end{array}$ & URL \\
\hline
\end{tabular}

Segui buscando en la Red de Bibliotecas Virtuales de CLACSO

http://biblioteca.clacso.edu.ar

Consejo Latinoamericano de Ciencias Sociales (CLACSO)

Conselho Latino-americano de Ciências Sociais (CLACSO)

Latin American Council of Social Sciences (CLACSO)

www.clacso.edu.ar

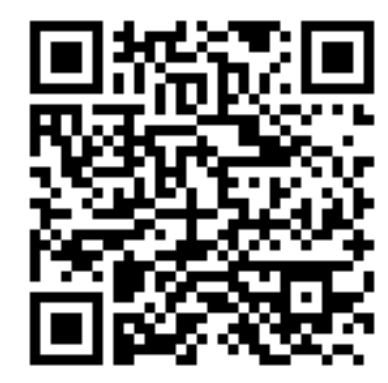




\title{
Fronteras y seguridad en el nuevo regionalismo estratégico
}

\author{
Martha Moncada Paredes*
}

\begin{abstract}
"El límite debe ser fijado y asumido libremente. Pero ¿cuál será la instancia habilitada para hacerlo? Al término de la odisea de la destrucción de toda norma impuesta por la trascendencia, la revelación o la tradición, la única autoridad razonable que queda es sin dudas el démos, o sea, los seres humanos emancipados que asumen su autonomía y se dan fronteras entre ellos y para ellos, constitutivas de un mundo común que contiene varios mundos comunes (...) recrear los límites y las fronteras es necesario no sólo para conjurar el colapso, sino también para reencontrar un mundo común".
\end{abstract}

Serge Latouche (2014: 135)

\section{Resumen}

Al considerar que las relaciones internacionales tienen una profunda vinculación con el espacio, el texto propone un análisis de las posiciones del ALBA-TCP, CELAC y UNASUR en relación al tratamiento de las fronteras. A través de este análisis se buscará identificar las rupturas o continuidades que pudieran existir por parte del nuevo regionalismo en torno a la temática de fronteras y discutir las razones que explican el renovado interés por fortalecer la integración al espacio nacional único de zonas que se han mantenido subalternizadas, como las regiones fronterizas. El texto discute el carácter parcial de la integración que se está llevando a cabo, supeditada a la dinámica del capital y a una política de seguridad y militarización; las implicaciones sobre las poblaciones fronterizas, especialmente sobre pueblos y nacionalidades cuyos territorios existían antes del Estado moderno, y los riesgos de supeditar la soberanía a intereses foráneos que persiguen mantener su hegemonía y garantizar el acceso a la riqueza natural que encierra América Latina. Frente al escenario descrito, sobresalen las tensiones entre un discurso que reclama autonomía en las relaciones internacionales y una práctica que reproduce la colonialidad del poder dentro de los Estados.

\section{Palabras clave}

Fronteras. Regionalismo. Seguridad. Territorio. Bienes comunes.

* Socióloga con una maestría en economía ecológica por la Facultad Latinoamericana de Ciencias Sociales -FLACSO-Sede Quito-. Actualmente está realizando un doctorado en "América Latina Contemporánea" con el Instituto Ortega y Gasset y la Universidad Complutense de Madrid. Este trabajo se desprende de su investigación doctoral "Entre fronteras: la ecología política de la frontera norte ecuatoriana". Ha trabajado temas relacionados con la ecología política y el estudio de conflictos de distribución ecológica, así como del metabolismo sociedad-naturaleza a partir de los conceptos y nociones del pensamiento decolonial.mart.moncada@yahoo.com 


\begin{abstract}
Considering the close links between international relations and geographical space, this document analyzes the positions of ALBA-TCP, CELAC and UNASUR regarding borders. The objective of this analysis is to find out the breaks and continuities that could exist within the policies around borders and to discuss the reasons that explain the renewed interest for consolidating State's territorial integrity into a unique national space, taking into account subaltern areas, as the border regions. The paper discusses that the current integration is biased and it is mainly defined by the dynamics of capital as well as security and militarization policies. This integration can affect communities living around the actual borders, particularly ancestral communities whose territories existed before the modern States. Furthermore, there is a chance that this method will risk sovereignty allowing external intervention that wishes to maintain its hegemony and its access to Latin America's natural patrimony. The described scenario brings out tensions between a position that claims for autonomy in the international relations and a practice that reproduces the colonial matrix.
\end{abstract}

\title{
Key words
}

Borders. Regionalization. Security. Territory. Common goods.

\section{Las fronteras ${ }^{1}$ como territorios subalternos}

¿Qué son las fronteras? El cambio de una a otra constitucionalidad, de una a otra identidad; la división administrativa entre dos realidades similares y al mismo tiempo distintas, el paso de un aquí a un allá, el lugar de pasaje, la zona de comunicación hacia lo otro, una abstracción divisoria de espacios; una puerta difícil de abrir y muchas veces imposible de cruzar; el lugar de separación entre Estados y comunidades; en ocasiones un área de confrontación y un territorio casi siempre catalogado como inseguro, caótico y peligroso.

El trazo de cualquier frontera representa una arbitrariedad y una simplificación de luchas sociales y de conflictos políticos y geopolíticos complejos. Rara vez, si es que alguna vez lo hace, la frontera tiene coincidencias con variables económicas, políticas y culturales; más bien representa una particular relación entre estas variables que puede ser transitoria o durable. De ahí que la frontera sea una línea divisoria imaginaria o real, muy pocas veces natural y casi siempre construida: muros, alambradas o zanjas suelen marcar los $247.000 \mathrm{~km}$ de fronteras que existen en el mundo y los $52.752 \mathrm{~km}$ de fronteras que se extienden a lo largo del continente americano.

La separación no es la única figura, o no es la que sobresale junto a la noción de fronteras. Éstas son, en paralelo, lugares de activa movilidad humana; de encuentro, reunión e intercambio; espacios de negociaciones y áreas apetecidas para formalizar acuerdos diplomáticos; son regiones generalmente caracterizadas por altos niveles de comercio y de interdependencias productivas; en las que se tejen relaciones culturales, deportivas, de amistad y de parentesco; son espacios donde pueden florecer identidades plurales y en los que destacan continuidades culturales. Para aquellos pueblos que comparten el mismo

\footnotetext{
${ }^{1} \mathrm{Al}$ hablar de fronteras o regiones fronterizas no se alude únicamente al límite internacional como dispositivo lineal sino a los espacios, dentro del territorio de un país, adyacentes a dicho límite.
} 
origen, que tienen iguales tradiciones y similares referentes, las fronteras pueden llegar a ser lugares carentes de significado. Como lo afirman Newman y Paasi, las fronteras están más presentes en quienes viven lejos de las áreas fronterizas; para quienes están asentados en estas áreas, las fronteras son parte de su vida cotidiana (1998: 203). Fronteras y territorialidad son por tanto nociones contextuales.

Hay fronteras más permanentes que otras, hay espacios más militarizados que otros; hay fronteras que admiten con relativa facilidad el paso de personas y otras que lo restringen; hay fronteras que cuentan con institucionalidad y movimientos comerciales más o menos formales mientras que otras permanecen descuidadas por los Estados.

Estas características, válidas para las fronteras entre los países, se extienden a cada frontera mirada de forma aislada pues como dice Albuquerque (2014), la frontera refleja la capacidad humana de producir discontinuidad en un espacio continuo. Su denominador común parece ser siempre la amalgama cultural, el contacto de los entramados sociales y políticos de los Estados, y un equilibrio siempre inestable entre alianza y conflicto social y político. A partir de la declaración de la "guerra contra el terrorismo" embanderada por los Estados Unidos a raíz de los atentados que sufriera la ciudad de New York (2001), las fronteras parecerían haberse convertido en los lugares por excelencia para poner en marcha diversos y sofisticados dispositivos y mecanismos de securitización.

De acuerdo a Agnew (2008), el propósito de las fronteras es doble. Tienen, por un lado, un fin instrumental, al demarcar la presencia institucional y los bienes públicos de un Estado. Desde esta perspectiva, actúan como una barrera de defensa a los derechos de propiedad. Por otro lado, las fronteras contribuyen a fijar la identidad política de un Estado a través de tres principios. El primero, y más tradicional, es la reivindicación de la soberanía, presente desde el siglo XVIII, entendida como "la autoridad para establecer lo que manda la ley (...) dentro de un territorio" (Rabkin, 2004, citado por Agnew, 2008: 179). El segundo principio tiene que ver con la existencia de metas y aspiraciones sociales al interior de un territorio (como la disminución de la pobreza, la construcción de empleo, el acceso a la educación y salud, etc.), lo que despierta un sentimiento de solidaridad nacional. El tercer principio guarda relación con la capacidad de las fronteras $-\mathrm{y}$ las políticas a asociadas a su gestión-, para controlar quien está dentro y quien "fuera" del Estado.

Sobre la base de estos principios, es posible concluir que las fronteras reflejan la política de muchas maneras. No son solo las políticas de delimitación/clasificación, sino también las políticas de representación y de identidad, vinculadas con narrativas de poder sustentadas en algún tipo de nacionalismo. El lugar de la frontera no es por tanto solo la línea limítrofe, sino el complejo proceso de construcción de la nación y de sus prácticas nacionalistas (Newman y Paasi, 1998).

Partiendo del reconocimiento de que cada frontera es única, que es un proceso históricamente contingente, es posible afirmar que no solo que hay una multiplicidad de fronteras desde el punto de vista de su conformación y especificidades sociales, culturales e históricas, sino que éstas pueden extenderse más allá de los límites de un Estado y adquirir una serie de manifestaciones (lenguaje, cultura, mitos, política, legislación, economía) (Johnson et al, 2011). Desde esta perspectiva es en la actualidad bastante difundida la idea de que existen múltiples fronteras y la aceptación de que éstas, más allá del límite geográfico fijo, tienen una serie de manifestaciones y expresiones. La multidimensionalidad y elasticidad de las fronteras es tal que hoy se reconoce que éstas pueden dislocarse 
espacialmente o dilatarse en el tiempo.

En términos de espacio, la frontera no es solo la línea divisoria. Existen de manera paralela marcos institucionales y dispositivos de distinto tipo (oficinas policiales, aeropuertos, oficinas de emisión de visados, etc.) con capacidad y poder para ampliar las prácticas de fronterización ${ }^{2}$ más allá de los límites internacionales entre dos Estados. El "biometric border", siguiendo la denominación propuesta por Louis Amoore (2006) al hablar de los nuevos sistemas de seguridad e información para controlar la movilidad humana, ha demostrado tener la capacidad y poder para crear y ampliar una serie de fronteras en diversos espacios.

Desde la lógica temporal, la frontera no se agota en la inmediatez del cruce fronterizo, sino que abarca procesos de mayor duración en el tiempo. Es precisamente el concepto de heterotopia -desarrollado por Foucault-, el que da cuenta que las fronteras se encuentran en espacios más allá de los límites fijados en el mapa. Abarcar estas distintas manifestaciones alrededor de la frontera, rebasaría el propósito de este trabajo. De ahí que a lo largo de este análisis únicamente se hará referencia a la frontera física cuyo poder y relevancia sería un error minimizar porque fueron construidas de manera artificial (Grimson, 2005a).

\section{América Latina, fronteras y Estado-nación}

Las fronteras han sido históricamente consideradas como áreas subalternas dentro de los Estados. Son por lo general las zonas menos atendidas en términos de cobertura de servicios básicos y presencia institucional, lo que las lleva a ostentar, en comparación con otras regiones de un país, los más bajos indicadores sociales y una serie de problemas no resueltos a los que en la actualidad se han sumado nuevos y complejos entramados de conflictos sociales y ambientales.

Por su relativa lejanía respecto a los centros administrativos, por la dispersión de los asentamientos que se extienden a lo largo de una frontera (porosidad) o debido a la complejidad de sus características físicas o sociales, aún en la actualidad subsisten controversias alrededor de la delimitación de algunos territorios nacionales, hay poca claridad en la tenencia de la tierra dentro de las regiones fronterizas; insuficiencia de políticas que alienten el mejoramiento social, productivo y económico de sus poblaciones y una falta de estrategias sostenidas y democráticas que impulsen la integración e incorporación de estas áreas al resto del Estado-nación. En las regiones fronterizas, la intervención del Estado se ha concretado, por lo general, en los ámbitos de la seguridad, lo que explica la presencia militar y policial característica en la mayoría de las fronteras, y en el cumplimiento de procedimientos administrativos y aduaneros a cargo de instituciones precariamente instaladas. Tal intervención sobre las fronteras sugiere que éstas han sido apreciadas fundamentalmente desde el contexto del conflicto, la separación y las barreras, no desde la paz, el contacto, la unificación o el intercambio.

\footnotetext{
${ }^{2}$ De acuerdo a María Lois (2014: 247), las prácticas de fronterización comprenden los discursos, representaciones y narrativas simbólicas para (re)construir las fronteras, tanto las territoriales como aquellas alejadas de los límites fronterizos, y las políticas y prácticas por medio de las cuales se materializan tales discursos y narrativas. Las prácticas de fronterización no tienen que ver únicamente con los Estados pues hay políticas a otras escalas que inciden sobre la conformación de las fronteras (acuerdos regionales, gobiernos locales, poblaciones asentadas en regiones fronterizas, empresas, medios de comunicación).
} 
En América Latina, la incorporación de los territorios fronterizos a los espacios nacionales únicos se ha realizado siempre en condiciones de extrema vulnerabilidad, sin considerar su realidad particular y forzando más bien la adopción del modelo de territorionación seguido por Europa, fundamentado en una propuesta territorial de Estado, el manejo centralizado de la política económica y la difusión de una concepción según la cual existe una equivalencia entre Estado, territorio e identidad. Tal enfoque guarda relación con los postulados de la geografía política clásica, difundidos principalmente por el geógrafo y etnógrafo alemán Friedrich Ratzel (1844-1904), que asociaba Estado y territorio en una sola unidad y a la construcción territorial como competencia única del Estado. Las fronteras eran consideradas como las membranas que garantizaban el crecimiento y solidificación de un núcleo: el Estado-nación.

Como lo sucedido en casi todo el mundo, incluso en Europa ${ }^{3}$, la fijación de las fronteras no fue el producto de diferencias culturales previas ni se corresponde con separaciones culturales manifiestas. Las fronteras tampoco fueron trazadas luego de que cada Estado-nación consolidara una dinámica particular dentro de un territorio ni se establecieron como resultado de la identificación de la "otredad". Las fronteras fueron impuestas luego de la colonización para favorecer una propuesta territorial de Estado embanderada por reducidos sectores sociales que se auto proclamaron portadores de una visión nacional, con el consiguiente desconocimiento y menosprecio hacia otras formas de organización y expresiones de territorialidad. Al priorizar el anclaje territorial como base para la construcción del Estado-Nación, los Estados latinoamericanos en ciernes abrían en lo posterior, las puertas al desafío del nacionalismo y de la construcción de la identidad nacional (Agnew, 2008).

Concluidos los procesos de independencia política, solo existían algunas fronteras fijas entre las posesiones españolas y portuguesas, así como entre los territorios españoles y los franceses. Los límites internos de los Estados fueron decididos sobre la base del principio uti possidetis, que implicaba tomar en cuenta el trazado de las últimas fronteras administrativas coloniales. Dejando a un lado las fronteras de los antiguos virreinatos, la delimitación de las nuevas fronteras tenía que seguir los límites marcados por las anteriores audiencias o capitanías (Bernecker, 2004).

La falta de precisión en algunos de estos límites determinó el estallido de conflictos durante gran parte del siglo XIX. En ningún caso se tomó en cuenta los territorios en los que vivían los pueblos originarios y cualquier intento en esta dirección, como la política de los jesuitas para establecer relaciones de intercomunicación cultural y de reordenamiento socioespacial, fue apreciada como un factor de inestabilidad del sistema colonial (Schallenberger, 2014).

De ahí que varios autores coincidan en afirmar que en el proceso de constitución de las fronteras nacionales de América Latina las tensiones fueron particularmente relevantes con las naciones indígenas. Su trazo no consideró la presencia de pueblos indios, no tomó en cuenta las realidades étnicas o lingüísticas previamente existentes (Porto-Gonçalves, 2006), ni reparó en la fragmentación de pueblos étnicos (como sucede entre los Awá, Siona y

\footnotetext{
${ }^{3}$ En el caso europeo hay autores como Agnew (2008) que explícitamente dudan si existía un sentido de "nación" durante la constitución de los Estados en el viejo continente. Lois y Cairo (2011: 18) señalan que las fronteras de los Estados europeos fueron fijadas a partir de la segunda mitad del siglo XIX (1850-60), a raíz del tratado de Westfalia que puso fin a las guerras que involucraban a varios países europeos.
} 
Secoya, o los pueblos indígenas Shuar y Achuar, divididos por las fronteras entre Ecuador y Colombia y Ecuador y Perú, respectivamente), la destrucción de las unidades políticas representativas o a la unión artificial de grupos étnicos diferentes o antagónicos. "Al ignorar el horizonte cultural previo, se contribuyó a forjar una nacionalidad fallida" (Navarro, 2011: 214). Pese a la existencia de fronteras, los pueblos indios localizados en estas áreas han seguido manteniendo históricamente una dinámica cotidiana de complementariedad y solidaridad, demostrando que la homogenización interna que persigue el trazo de las fronteras generalmente es confrontada en las regiones fronterizas debido a la pre-existencia de lazos afectivos y relaciones comunitarias o de formas de organización social alternativas (Anderson y O’Dowd, 1999: 600).

Una vez constituidos los Estados latinoamericanos, la consolidación de las fronteras y de la soberanía territorial fue un proceso que se extendió a lo largo de los siglos XIX y XX. Durante el siglo XIX, especialmente desde 1850 en adelante, formadas ya las jóvenes naciones e insertadas en el sistema capitalista mundial, muchos de los conflictos tuvieron relación con el acceso a recursos naturales que podían ofrecer los territorios latinoamericanos (García Pérez, 2005: 218).

Con excepción de Cuba y Puerto Rico, a lo largo del siglo XX, la mayoría de los Estados se vieron involucrados en luchas fronterizas como consecuencia de las diferencias entre los límites territoriales compartidos, "el impreciso, ambiguo o mal trazado de los mismos en el tiempo de la guerra por la independencia; la difícil y compleja orografía peculiar de los espacios objeto de disputa; los afanes expansionistas de algunos gobiernos; el aislamiento geográfico de ciertos países (entiéndase la falta de salida al mar); las políticas tendentes a dar algún impulso al débil o muy decaído orgullo nacional, y, con más frecuencia aún, la pugna por controlar los recursos económicos, (...), de un determinado territorio" (Ibid.: 219).

Sin el ánimo de presentar un detalle exhaustivo de los conflictos, conviene recordar que en épocas relativamente recientes como 1978, Argentina y Chile estuvieron al borde de la guerra por diferencias en el control del canal de Beagel; que a finales de los años setenta, subió la tensión entre Chile, por una parte, y Bolivia y Perú por otra; que en 1982, Argentina y Reino Unido protagonizaron un conflicto por el control de las Islas Malvinas. En 1987 Colombia y Venezuela tuvieron un enfrentamiento naval conocido como la "Crisis de la Corbeta Caldas". En el año 1995 se cerró el diferendo limítrofe que mantuvieron Ecuador y Perú por cerca de ciento setenta años, desde 1830, cuando la firma del Protocolo de Río que concluyó con la guerra de 1941 entre estos dos países, descuidó precisar los límites de un espacio de $78 \mathrm{~km}$ entre los dos países.

Hacia fines del siglo XX las fronteras territoriales de los países de América Latina estaban ya prácticamente definidas, restando por resolver los límites de las fronteras marítimas entre algunos Estados y puntuales conflictos territoriales. Una reciente investigación llevada a cabo por Viviana García Pinzón (2014) destaca en la actualidad nueve conflictos fronterizos latentes en Suramérica. Algunos se remontan al pasado, mientras otros son la consecuencia de la revisión del Derecho Internacional al Mar y la consiguiente extensión de la jurisdicción marítima a 200 millas. Tres conflictos giran en torno a la disputa por el control de territorios: entre Bolivia y Chile, que involucra el histórico reclamo de Bolivia por una salida al mar; entre Argentina e Inglaterra alrededor de las Islas Malvinas y entre Colombia y Venezuela que disputan las islas Los Monjes. Seis conflictos están referidos a la delimitación entre fronteras marítimas y ríos y tienen como 
telón de fondo el acceso a recursos hidrocarburíferos: entre Guyana Francesa y Surinam, entre Surinam y la República Cooperativa de Guyana, entre este último país y Venezuela; entre Perú y Chile, entre Venezuela y Trinidad y Tobago, y entre Nicaragua y Colombia.

\section{Fronteras como nuevos territorios de colonización}

Aunque consolidados en su base territorial, dentro de los Estados latinoamericanos subsisten áreas subalternizadas como las fronteras. La fijación de los límites territoriales no implicó modificar los críticos indicadores sociales que caracterizan a las regiones fronterizas. Con el paso del tiempo éstos, por el contrario, en muchos casos han tendido a agudizarse debido al surgimiento de nuevos y complejos problemas. Un recorrido por las áreas fronterizas de América Latina advierte que junto a la precaria calidad de vida, a la ausencia de oportunidades de trabajo, a la mala calidad o inexistencia de servicios públicos básicos, incluido el acceso a la educación y una adecuada cobertura sanitaria; a las dificultades de comunicación y accesibilidad, a las debilidades de las instituciones locales que conviven con modelos fuertemente centralistas, han aparecido nuevos y complejos problemas vinculados con el tráfico y trata de personas, la producción y el tráfico de drogas, el comercio de armas y municiones, la depredación de bosques y la minería ilegal, por citar algunos de los problemas más relevantes presentes en la mayor parte de las fronteras de la región.

Las fronteras fueron espacios a los que las sociedades nacionales trataron con abierta indiferencia. Ocupadas muchas de estas áreas por pueblos indígenas, fue latente el marcado desprecio hacia sus formas de vida y de organización, consideradas como arcaicas, primitivas e intrascendentes. La excentricidad, la falta de autonomía y la asincronía, tres propiedades identificadas por Germán Palacio (s/f, citado por Alimonda, 2011: 34) para hablar de la subalternidad de la Amazonía, grafican el tratamiento concedido por los Estados latinoamericanos a estas regiones. La excentricidad se refiere a su incorporación a los territorios nacionales como áreas inexploradas y desconocidas. La falta de autonomía alude a su inclusión al Estado nacional a partir de operaciones militares de conquista, convirtiendo a las fronteras y otros territorios subalternizados en "dependencias directas de los poderes ejecutivos nacionales, en un régimen que podría denominarse de "colonialismo interno"" (Ibid.: 35). La asincronía da cuenta que la historia de estas regiones no acompaña la periodización de las sociedades que las contienen pues su ritmo está vinculado generalmente a una temporalidad distinta o a la prevalencia de formas de organización y producción no enteramente capitalistas.

El olvido sobre las áreas subalternizadas se revierte cada cierto tiempo en función de coyunturas particulares. Los conflictos limítrofes, por ejemplo, se traducen en una mayor presencia militar y en un despliegue de fuerza en las áreas comprometidas, lo que al parecer, por el momento, no resulta en un escenario probable para la mayor parte de países latinoamericanos. En otras ocasiones, los Estados se sienten obligados a regresar a ver a las áreas subalternizadas debido a la presión ejercida por las poblaciones exigiendo el cumplimiento de derechos postergados. Esta realidad, no muy frecuente, motiva la intervención estatal a través de la construcción o funcionamiento de algún servicio, en la espera del surgimiento de nuevas reivindicaciones. Lo más usual es que las áreas subalternizadas cobren un interés particular cuando en tales territorios se identifican posibilidades de explotación de algún recurso natural, cuando las necesidades de acumulación de capital demandan la ampliación de las superficies agrícolas, el aumento de las operaciones de prospección y explotación minera e hidrocarburífera o la realización de grandes obras de infraestructura. En estos casos, la maquinaria gubernamental pone en 
movimiento diversos mecanismos para avanzar sobre territorios aparentemente despoblados o habitados por poblaciones indígenas (Grimson, 2005b; Alimonda, 2011).

La ampliación de la frontera extractiva sobre áreas que han ocupado un lugar secundario dentro de los Estados Nacionales motiva el desplazamiento de personal y equipos y la construcción de infraestructura, a lo que siguen por lo general, procesos de colonización planificados o no. En la actualidad, parecerían existir un conjunto de condiciones que nuevamente dejan a un lado el confinamiento al que han estado sometidas las áreas subalternizadas a tal punto que en varios países de la región se atestigua un interés creciente por parte de los gobiernos para impulsar su incorporación a la dinámica nacional. Argentina ha regresado a ver a la Patagonia, Brasil ha reavivado su interés por las zonas más lejanas de su extensa amazonia; Ecuador ha desplegado un discurso de desarrollo e inclusión hacia regiones hasta hace relativamente pocos años atrás ausentes de las principales preocupaciones gubernamentales.

La paulatina incorporación de las regiones subalternas al orden nacional o la consolidación de la unidad del Estado-nación, sigue procesos similares a aquellos identificados por Quijano (2000) al examinar la constitución histórica de América Latina. En efecto, en la colonización de estas áreas, y la concomitante transformación de su espaciotiempo, toman lugar dos procesos que se refuerzan mutuamente: (1) la diferencia cultural que coloca a las poblaciones que tradicionalmente habitan las áreas subalternizadas en una situación de inferioridad respecto a los "colonos", empresas y fuerzas militares y policiales que provienen de regiones hegemónicas pertenecientes al mismo espacio nacional; y, (2) la articulación del trabajo y recursos de estas regiones en función de los requerimientos del proceso de acumulación interno y del mercado mundial.

En relación a la diferencia cultural como medio para justificar la incorporación de territorios, trabajo y recursos no plenamente adscritos al espacio político único y dominante, es usual colocar a las poblaciones que tradicionalmente habitan áreas subalternizadas en una situación de inferioridad. Consideradas como espacios de pobreza, de extrema vulnerabilidad, como "oriente", lugares sin habitantes, fronteras o zonas "atrasadas", el Estado busca revertir dicha inferioridad a través de la imposición de una lógica de progreso y de una única vía de desarrollo, y su adscripción a un espacio nacional único (Navarro Floria, 2011). La introducción de la visión de progreso se constituye en un argumento para legitimar acciones que incidirán en su transformación.

Para forzar la articulación de áreas hasta ahora escasamente atendidas, argumentos sorprendentemente similares a aquellos utilizados durante el pasado colonial entran nuevamente en boga. El deber y la buena intención de apoyar a que las poblaciones asentadas en áreas escasamente atendidas por el Estado trasciendan el "atraso" que soportan o la importancia de aprovechar las riquezas que dispone el país con el propósito de destinar los recursos económicos que genere su explotación al impulso de procesos de desarrollo (definidos por quienes detentan el poder político), son argumentos que guardan similitud con el papel redentor que se auto-asignaron los conquistadores o con el discurso de las ventajas comparativas con el que la corriente económica dominante justificó la división del mundo entre países exportadores de materias primas y países especializados en la fabricación de bienes industriales.

Este proceso, que entraña una profunda violencia epistemológica y semiótica, está irremediablemente asociado a la alteración de la dinámica local en la medida en que, como 
lo señala Navarro Floria (Ibid.), la re-significación que toma lugar prescinde de la historicidad y cultura existentes para imponer la maquinaria representacional del Estado. Los cambios exógenos introducidos al margen de los intereses de las poblaciones locales acelerarán la destrucción de sistemas de representación y de simbología que hasta entonces favorecieron la cohesión y la identidad social y cultural, transformarán irreversiblemente las formas de existencia con la naturaleza circundante, suplantarán la propiedad comunal y los derechos consuetudinarios, por la propiedad privada o desconocerán las potencialidades del trabajo asociativo para dar paso al predominio del empleo individual. La existencia de otras formas de vida o al cumplimiento de disposiciones constitucionales y legales, así como de acuerdos internacionales que protegen el acceso a territorios o la integridad cultural de los pueblos indios no suelen ser elementos considerados por los Estados al momento de decidir la ampliación de la frontera extractiva y la incorporación de áreas subalternas.

No es casual que en los territorios no plenamente incorporados al espacio nacional único, sobresalga la presencia de pueblos indios. En las áreas subalternas, estos pueblos coexisten junto a una importante riqueza natural que, en las regiones fronterizas, por lo general se extiende a lo largo de ecosistemas compartidos entre dos o más Estados, bajo la forma de reservorios de bienes comunes que no conocen fronteras. Desde el punto de vista de la ecología política, tanto la forma de vida de estos pueblos como su visión sobre la naturaleza explican el mantenimiento de importantes reservorios de biodiversidad contenidos en entornos escasamente alterados. Sin idealizar el papel que han desempeñado los pueblos indígenas, ellos han demostrado ser "(l) os guardianes más eficaces (...) de los bosques y florestas (...), a condición de que sus formas de organización no sean agredidas $\mathrm{y}$ debilitadas, y de que no se vean forzados a modificar bruscamente sus patrones de reproducción para satisfacer los desenfrenos del "progreso"' (Díaz-Polanco, 1997: 24). Desde la perspectiva de la crítica poscolonial, antes que reconocer el aporte de dichos pueblos, su incorporación al espacio nacional único supone poner en marcha una red de relaciones asimétricas que como sostiene González Casanova, "trata a las comunidades indias como colonias internas, como sociedades colonizadas, dentro de los límites de un Estado nacional, sujeto igualmente a procesos de dominio de mayor escala" (1965, citado por Báez Landa 2010: 62).

De ahí que parezca adecuado extrapolar la conclusión a la que llega Achille Mbembe al estudiar el proceso de formación de las actuales fronteras en el África para el caso de América Latina: "La conexión entre un Estado y un territorio es meramente instrumental, por lo que el territorio solo tiene sentido, en el plano político, como espacio privilegiado para el ejercicio de la soberanía y la autodeterminación y como marco ideal para la imposición de la autoridad" (2008: 171). La escasa cohesión territorial, política e identitaria de los Estados explica que las fronteras y otras áreas de difícil acceso, sea por su morfología o su clima; los parajes concentradores de alta biodiversidad, como la cuenca amazónica que comparten siete países de América Latina, y los espacios habitados por pueblos indígenas, afrodescendientes o minorías culturales, ocupen un lugar subordinado junto a otras hegemonías territoriales (Alimonda, 2011) que se atribuyen la representación de un interés nacional único, una identidad compartida, un sentido del nosotros y una constitucionalidad, y que actúan dentro de un solo mapa delimitado por fronteras fijas y por la soberanía del Estado-nación.

Al encasillar diversas temporalidades en un solo tiempo mundial, que no es otro, sino el que marca el poder hegemónico, Mbembe identifica que un denominador común de dicha domesticación es la dominación del espacio y de los diferentes usos que de este espacio 
hacen las poblaciones que lo habitan. "La domesticación persigue desconectar las personas de las cosas y siempre dependerá de la historia y cultura locales y de la interacción de intereses cuyos factores determinantes no siempre conducen en la misma dirección" (2008: 168). Atrás de tal domesticación no está únicamente el afán por sintonizar todos los espacios al tiempo mundial, por lo general la conquista de las temporalidades otras está asociada a los recursos que contienen sus espacios, de lo que resulta un valor mayor para las cosas que para las personas. De ahí que frente a los supuestos beneficios que traería consigo el desarrollo, poco importan las dificultades, pérdidas y rupturas que soporten los seres humanos, el surgimiento de diversas formas de violencia, o la transformación ecológica y cultural de las comunidades, lo cual conduce a señalar el segundo proceso que motiva la incorporación de áreas subalternas referido a la articulación del trabajo y recursos a los requerimientos del proceso de acumulación interno y del mercado mundial.

En este caso, las motivaciones son claramente de orden económico y suponen la puesta en marcha de renovados procesos de acumulación por desposesión -para usar el concepto acuñado por David Harvey-. Estos procesos implican la apropiación ilegal y violenta de territorios que se mantienen relativamente fuera del mercado, lo que conlleva la aplicación de mecanismos extra-económicos (políticos y coercitivos) de expropiación de la tierra, de la riqueza natural y de la fuerza de trabajo para controlar y comercializar los bienes comunes $^{4}$ que contienen dichos territorios (agua, biodiversidad, bosques). Al apropiarse de un espacio-temporalidad, los seres humanos buscan apropiarse al mismo tiempo de la naturaleza, transformando bienes comunes de la naturaleza en commodities para el mercado.

La ampliación de procesos de colonización interna, y la concomitante transformación del valor de uso de los bienes comunes contenidos en áreas hasta hace poco olvidadas está motivada, en gran parte, por los cada vez mayores requerimientos de materiales y energía de las economías industrializadas, la relativa mejora de los términos de intercambio de las materias primas presente hasta hace unos pocos años atrás ${ }^{5}$; la alta disponibilidad que tienen los países de América Latina de minerales, petróleo, bosques, agua, biodiversidad y tierra agrícola, y la importancia concedida por algunos gobiernos de contar con los recursos

\footnotetext{
${ }^{4}$ El concepto de bienes comunes proviene de la tradición anglosajona y señala que la naturaleza es un patrimonio universal imprescindible para la realización de la vida. Al convertir los bienes comunes en commodities para el mercado, no solo que se arrasa con la noción según la que la naturaleza es el repositorio de los poderes de la creación, sino que se desconocen derechos consuetudinarios, pasando de lo común a lo privado (Shiva, 1995; Svampa, 2011).

${ }^{5}$ CEPAL advirtió en el año 2013 que el aumento de los términos de intercambio registrado antes del 2010 y hasta el 2012 podría iniciar un descenso, con diferencias entre países y los rubros exportables (2013: 28-30). En efecto, luego de una década en la que se experimentó un crecimiento inusitado de los precios de las materias primas, a partir de inicios del año 2015 éstos comenzaron a caer. El petróleo cuyo precio había fluctuado alrededor de los 30 dólares o menos desde finales de los años 90 del siglo pasado, inició una escalada alcista desde aproximadamente el año 2003, luego de la invasión a Irak. A partir de entonces, su precio tuvo un crecimiento sostenido hasta llegar a superar, en el año 2008, los 100 dólares por barril de petróleo y aún sobrepasar los 150 dólares a mediados de ese mismo año. En la actualidad y luego de un errático comportamiento, el precio del petróleo se situó en los mismos niveles anteriores a 2008: menos de 50 dólares por barril. Una tendencia parecida se registró en el precio de los minerales. El oro, por ejemplo, que se mantuvo alrededor de los 400 dólares entre 1993 y el 2006, experimentó una impresionante subida desde este último año hasta el 2011, llegando a 1800 dólares la onza de oro, para comenzar nuevamente a caer en los últimos cuatro años, localizándose en la actualidad en 1000 dólares la onza o menos. Comportamientos similares se registraron en otras materias primas que América Latina históricamente han sido parte de sus exportaciones
} 
económicos necesarios para financiar el desarrollo de la infraestructura social y de los servicios y mantener en funcionamiento los grandes programas sociales de transferencias monetarias y subsidios con los que están sosteniendo la atención de las necesidades básicas de amplios sectores poblacionales.

Al tratarse de fronteras y regiones fronterizas, los mecanismos de incorporación de estos territorios y las estrategias de acumulación por desposesión suelen revestir facetas más complejas a las señaladas en la medida en que la expansión de las fronteras internas está respaldada por el pretexto del fortalecimiento de la soberanía y el despertar de sentimientos nacionalistas. Un primer camino para la integración de las regiones fronterizas ha sido la promoción de estrategias de colonización adoptadas por los Estados especialmente desde la segunda mitad del siglo XX. Bajo el argumento de desarrollar fronteras vivas capaces de consolidar la soberanía de la nación, los Estados incentivaron la colonización de algunas de las áreas fronterizas, así como de territorios con densidades demográficas bajas. De manera espontánea poblaciones de provincias y departamentos ubicados al interior de los países latinoamericanos asumieron el reto de conquistar territorios, al mismo tiempo que se daba paso a la instalación de empresas privadas para la realización de diversas actividades de prospección y exploración de la riqueza natural contenida en dichas áreas. El impulso a la colonización se sustentó en la ecuación según la que la integridad territorial y el resguardo de las fronteras equivalía al fortalecimiento de la nación.

La construcción de infraestructura ha sido utilizada como otro de los medios para revertir el aislamiento y las dificultades de acceso que justificaron la poca atención concedida las fronteras o la nueva voluntad política para forzar su adscripción al espacio político único. Como señala Grimson (2005b), este proceso puede servir para gestionar la frontera o para expandir un sistema sobre otro e imponer una particular conformación social y económica por sobre otras formas de vida. La dirección que se imponga dependerá de los entrelazamientos globales, regionales, nacionales y locales que definirán la orientación de la infraestructura y equipamiento construido en un área particular.

Como un elemento complementario a la construcción de infraestructura funcional al desarrollo de alguna actividad económica que puede afectar tierras comunitarias y trasgredir la dinámica social y productiva imperante, es común que se creen estructuras organizativas paralelas o que junto a las obras monumentales se construyan facilidades para las comunidades con el objeto de obtener el consentimiento de la población y minimizar la ocurrencia de manifestaciones de resistencia o rechazo (Machado Aráuz, 2010). Estas prácticas, típicas en empresas multinacionales, se han extendido también hacia los gobiernos, incluso de aquellos que dicen abanderar posturas post-neoliberales. Es el caso de las llamadas Ciudades del Milenio lanzadas por el Presidente ecuatoriano Rafael Correa en el 2011. Las Ciudades del Milenio ${ }^{6}$ son nuevos poblados construidos con las regalías petroleras, en lugares cercanos a los centros de extracción de petróleo o minería en la Amazonía, que "parecen aldeas típicas de los EEUU, con trazados reticulares de viviendas individuales situadas alrededor de una escuela, un centro de salud, unos campos deportivos, una unidad de policía (...) las viviendas están distribuidas a parejas casadas; el acceso a la

\footnotetext{
${ }^{6}$ Las dos primeras Ciudades del Milenio son Playas de Cuyabeno y Pañacocha, inauguradas en 2013 y 2014 respectivamente. Ambas son habitadas por comunidades indígenas afectadas por la apertura del campo de petróleo de Pañacocha, situado en el norte de la Amazonía. Para los siguientes años, la perspectiva es construir 200 Ciudades del Milenio "alrededor de las regiones ricas en recursos de la Amazonía, con la finalidad de facilitar la expansión de la frontera extractiva" (Wilson, Bayón, Diez, 2015: 18).
} 
selva y al río está obstruido por verjas y paseos; y los habitantes tienen prohibido tener animales, cultivar, fermentar chicha, o modificar las estructuras de sus casas" (Wilson, Bayón, Diez, 2015: 16).

Las dos opciones señaladas no son excluyentes la una de la otra y resultan más bien complementarias. Olas de colonización son seguidas por la instalación de infraestructura, de la misma manera que la puesta en marcha de obras físicas o actividades económicas alientan procesos de inmigración desde el interior de los países. La diferencia entre una y otra modalidad de integración de las áreas subalternizadas está dada por la racionalidad subyacente en cada caso. Mientras la construcción de carreteras y puentes persigue fundamentalmente fortalecer el comercio, facilitar la circulación de productos y mercancías, o generar las condiciones propicias para la exploración y explotación de un recurso natural, la colonización resulta con frecuencia en una suerte de válvula de escape para reubicar fuerza de trabajo que no puede ser absorbida por el mercado laboral, para disminuir las presiones por la mala distribución de la tierra o para desfogar problemas internos como sucedió en Ecuador en la década de 1960 e inicios de la siguiente ante la sequía que afectó a las provincias de Loja y Manabí y que ocasionó la inmigración de miles de familias hacia la Amazonía norte.

Sea a través de la construcción de infraestructura o del impulso de procesos de colonización interna, la incorporación de las fronteras al espacio nacional único ha redituando los rasgos de la matriz colonial con repercusiones en diversos ámbitos: en lo social y cultural, aumento de la conflictividad social y deterioro de la calidad de vida de las poblaciones asentadas históricamente en dichas áreas, con impactos especialmente severos sobre los pueblos indígenas; en lo referido a la movilidad humana, incremento de las restricciones para un tránsito humano fluido, incluso de poblaciones que comparten entre sí una historia común, lazos afectivos y familiares y mantienen una red de comercialización e intercambio apegada a sus necesidades; en términos de seguridad, una creciente militarización de las fronteras, con consecuencias sobre la criminalización de las actividades cotidianas de la población; en lo económico, la formación de enclaves de extracción de recursos, cuyos beneficios no se quedan en el área ni generan posibilidades de trabajo para la población local.

En los últimos años, la adscripción de las fronteras al espacio nacional único parecería descansar sobre un nuevo elemento: la entrega de importantes territorios a empresas privadas para la operación de represas, establecimiento de cultivos, explotación de minería o petróleo, actividades en las que el trabajo de las poblaciones locales no tiene sino una importancia marginal debido a los escasos requerimientos de trabajo de algunas de estas actividades económicas o a la complejidad técnica que entraña la operación de otras. En esta nueva lógica se privilegia la articulación de los recursos de las áreas fronterizas en función de los requerimientos del proceso de acumulación interno y del mercado mundial, $\mathrm{y}$ se presiona por el "vaciamiento territorial" en el sentido que las poblaciones originalmente asentadas en estos territorios son expulsadas de sus lugares de pertenencia ${ }^{7}$. Uno de los

\footnotetext{
${ }^{7}$ El reasentamiento de comunidades indígenas o su desplazamiento a otras áreas provocado por la instalación de actividades económicas que afectan la reproducción de su vida no está exento de una carga de racismo ambiental y del surgimiento de refugiados ambientales, es decir, de aquellas personas que se ven forzadas a abandonar sus hogares y su tierra para dar paso a la operación de actividades económicas y extractivas incompatibles con el mantenimiento de una vida digna. Este es un ámbito que requiere de una mayor observación e investigación pues mientras la narrativa
} 
casos más dramáticos al respecto es el registrado en Colombia con el desplazamiento de más de 5 millones de personas víctimas del conflicto armado y el consecuente control del territorio tanto para el cultivo de coca, como para la extensión de las plantaciones de palma africana, con especial crudeza en las regiones fronterizas con Ecuador.

Frente a la complejidad subyacente en el tratamiento otorgado a las regiones fronterizas, cabe interrogar ¿cuáles son los cambios, si los hay, en el tratamiento de las fronteras por parte del nuevo regionalismo latinoamericano?, ¿cuáles han sido las respuestas que han desarrollado los Estados latinoamericanos y las nuevas instituciones regionales frente a los territorios y, de manera especial frente a sus fronteras?, ¿cuáles son las continuidades o cambios que ha definido el nuevo regionalismo, inspirado en un posicionamiento autónomo frente a Estados Unidos, en relación a los temas fronterizos y lo que éstos involucran? Tales interrogantes adquieren una particular relevancia a la luz de la nueva geopolítica de reparto territorial mundial, donde Estados Unidos busca desesperadamente recomponer su hegemonía.

\section{Reorganización territorial y nuevas fronteras extractivas}

David Harvey (2004) habla de la reorganización espacial como una estrategia para absorber los excedentes de capital generados por las crisis de sobre producción que cada cierto tiempo afectan el funcionamiento de la economía mundial. Al invertir los excedentes de capital en proyectos de largo plazo, como la construcción de infraestructura o la apertura de nuevos mercados, o propiciar una combinación de ambos, se difiere la circulación de los excedentes actuales, de la misma manera que sucedería si éstos fueran colocados para financiar gastos sociales, y se sientan las bases para poner en movimiento renovados procesos de acumulación de capital. "La tasa de retorno de estas inversiones a largo plazo (...) depende de la evolución de una dinámica sostenida de acumulación en el país receptor" (Ibid.: 104). Esta fue la expectativa del Plan Marshall en Europa cuando Estados Unidos comprendieron que "su propia seguridad económica residía en la revitalización de la actividad capitalista en estos lugares" (Ibid.).

No sería aventurado sugerir que en la actualidad un proceso similar estaría tomando lugar en América Latina. El territorio de la región - 20 millones de kilómetros cuadrados- y un mercado de 600 millones de habitantes (Boron, 2013: 97) no son despreciables para impulsar renovados procesos de acumulación de capital, junto con la disponibilidad de recursos de valor estratégico para la operación de capitalismo a nivel mundial.

En línea con lo anterior, Stedile (2013) sostiene que ante la inestabilidad del dólar y la caída de la tasa de interés, una de las estrategias para proteger los capitales de los grandes grupos económicos y detener la caída de la tasa de ganancia consiste en la compra de activos fijos como tierra, minas, materias primas agrícolas, agua y territorios con alta biodiversidad. A través de la compra de tales activos, el capital financiero se apropia de las bolsas de mercancías agrícolas o de minerales para especular en el mercado o transformar el dinero en mercancías futuras, lo que contribuye al incremento relativo de los precios de las materias primas. Los mayores precios de los bienes agrícolas no alimentan únicamente las ganancias extraordinarias de las empresas monopólicas ${ }^{8}$, sino que presionan a la quiebra de los

dominante interpreta algunos reasentamientos y desplazamientos rurales-urbanos como parte del progreso, lo que se esconde es la inequitativa distribución de los recursos.

${ }^{8}$ Stedile (2013) afirma que a nivel planetario cincuenta empresas transnacionales controlan la mayor parte de la producción y el comercio mundial agrícola. 
pequeños productores que no pueden competir con los volúmenes y capacidad de producción y distribución de las grandes empresas. Los mayores precios de las materias primas atraen la atención de los gobiernos de los países no industrializados por acceder a divisas, forzando una nueva fase de reprimarización de nuestras economías. Tal proceso no solo afecta a países como Bolivia, Ecuador o Perú que cuentan con una fuerte tradición extractiva, sino incluso a aquellos países con patrones económicos más diversificados como Brasil y Argentina (Svampa, 2011).

De ahí que en acuerdo con lo que sostiene Horacio Machado (2010) se pueda concluir que no en vano, a partir de la década de los 90 del siglo pasado, el capital transnacional ha propiciado una drástica reconfiguración territorial de la región con la creación de mega zonas de monocultivos, la instalación de proyectos extractivos de gran escala y la redefinición integral de las funcionalidades sociales y ecológicas de los territorios. En esta lógica, es impensable la existencia de proyectos territoriales autónomos que atentarían contra los intereses de control del territorio y de la población fomentados desde el Estado (Escobar, 2005: 54).

En medio de la actual crisis del capitalismo, es evidente que el interés por contar con nuevos mercados para mantener y aún ampliar los niveles de acumulación y la puesta en marcha de agresivos procesos de financiarización de la economía, con sus repercusiones sobre la reconfiguración territorial de América Latina, contribuyen a explicar la dinámica de crecimiento y reorganización territorial que está tomando lugar en el sub-continente. Lo anterior se combina con el interés de Estados Unidos, así como de otras economías que representan una competencia y una amenaza a su dominación sobre la región, de garantizar el acceso y control a la riqueza natural de nuestros países.

Al respecto merece la pena recordar ciertos datos: la mayor reserva petrolífera del planeta está en Venezuela según lo ha confirmado la OPEP; América Latina dispone más de un quinto de todos los bosques y casi la mitad del total de agua potable del planeta y el 35\% de la potencia hidroeléctrica global: solo el cono sur contiene el $25 \%$ de las reservas de agua dulce de la Tierra con 1,19 millones de $\mathrm{km}^{2}$ en el acuífero del Guaraní, el más grande del mundo (Delgado Ramos, 2001). Perú, Chile, Brasil, Argentina, Bolivia y Venezuela están entre los diez primeros países mineros del mundo y la región en su conjunto contiene casi un tercio de las reservas mundiales de cobre, bauxita y plata, el $27 \%$ del carbón, el $5 \%$ del uranio y uno de los mayores depósitos de níquel, cobre, litio y niobio a nivel mundial (Sánchez Alvabera y Lardé, 2006, citado por Machado Aráoz, 2010: 313). Al mismo tiempo que el subcontinente posee el $40 \%$ de todas las especies animales y vegetales existentes en el planeta, cobija a cinco de los diez países más biodiversos del mundo (Brasil, Colombia, Ecuador, México y Perú) y alberga, en sus ríos interiores, a una cuarta parte de la riqueza ictícola mundial (Boron, 2013), lo que los convierte en una fuente potencialmente rentable para la industria farmacéutica o de alimentos.

El interés de los Estados Unidos sobre los minerales, petróleo, agua y biodiversidad de América Latina no es reciente. Ya desde 1945 Estados Unidos se fijó como meta el acceso a los recursos naturales a través de un régimen multilateral que perseguía acercar a los países de la región a su influencia, alejándolos al mismo tiempo de la ascendencia que pudiera ejercer la ex Unión Soviética y el campo socialista. Para ese entonces la actuación de los gobiernos reformistas de Guatemala y Bolivia, principalmente, constituían motivo de profunda preocupación, lo que motivó a que Estados Unidos promueva una política que, al tiempo que implementaba supuestas estrategias de apoyo y establecía los arreglos necesarios 
para el ingreso de inversiones estadounidenses, garantizaba el fortalecimiento de la presencia militar en la región. En el primer ámbito sobresale la denominada asistencia para el desarrollo a través de la Alianza para el Progreso (1961) que sirvió para consolidar las bases del adoctrinamiento de militares en contra insurgencia.

Hacia el interior de las economías latinoamericanas, las décadas de los sesenta y setenta se caracterizaron por un manejo de corte proteccionista que fomentó la construcción de infraestructura productiva y favoreció la creación de empresas públicas, muchas de las cuales quedaron en manos de militares. Esta realidad la atravesaron, y a veces con más fuerza, los países bajo dictaduras autoritarias y represivas como las del Cono Sur.

Con el advenimiento de regímenes democráticos en América Latina, el control público de los recursos naturales estratégicos comenzó a diluirse a favor de políticas económicas neoliberales para cuya implementación los ejércitos de la región cumplían un importante papel de guardianes de la democracia y el orden, sin actividades claras en materia de defensa (Garzón, 2012). En ningún caso la instalación de regímenes democráticos se tradujo en una disminución del tamaño de los ejércitos, ni en una merma en el gasto militar del continente, dos atributos que se prolongan aún en la actualidad. La configuración de nuevos escenarios políticos dentro de la región mantuvo a sus viejas Fuerzas Armadas.

La orientación neoliberal que primó desde la década de 1980 hasta inicios del siglo actual, se corresponde con el renovado énfasis que otorgó Estados Unidos al control y acceso de los recursos naturales estratégicos. Hacia finales del siglo pasado, Estados Unidos subrayó la preeminencia de sus intereses y su voluntad para mantener el nivel de vida de despilfarro sobre el que descansa su economía, por sobre cualquier decisión interna de los países dueños de las riquezas naturales. La ley estadounidense del 28 de junio de 1980 declaraba que:

"(s)i un país que es un gran productor de petróleo o de minerales decide conscientemente reducir su producción y aumentar sus precios, o si experimenta transformaciones a causa de un movimiento revolucionario, las repercusiones pueden incidir tanto en el suministro como en los precios (...) y el interés nacional presente y futuro de Estados Unidos exige disponer de recursos minerales sólidos independientemente de las políticas de exportación aplicadas por los países extranjeros" (Chemillier-Gendreau, 2013: 15).

No es posible desconocer que la riqueza natural de América Latina ha constituido un atractivo permanente para Estados Unidos. Su estrepitoso fracaso para apropiarse del petróleo y otros minerales de los países del medio Oriente, hicieron redoblar su atención hacia la región, sobre todo en un momento en que nuevas economías como China, India, o Rusia, igualmente necesitadas de vastos flujos de materiales y energía, han regresado a ver con interés la oferta que pueden proporcionar los países latinoamericanos.

Con el propósito de mantener su dominio, Estados Unidos se ha lanzado a una alocada carrera hacia el control excluyente de bienes comunes y ha precipitado la militarización de las relaciones internacionales (Boron, 2013). Su seguridad, entendida como el mantenimiento del stock necesario de recursos naturales para el funcionamiento de su economía, y el control y expansión territorial son, para Estados Unidos, dos nociones vinculadas que se refuerzan mutuamente debido al predominio que tiene el denominado 
complejo militar-industrial sobre la definición de las metas y objetivos de política de dicho país.

\section{Las fronteras dentro del nuevo regionalismo}

A partir de inicios de la primera década del siglo XXI, América Latina presenció el ascenso al poder de una serie de regímenes alejados del neoliberalismo a ultranza que se aplicó en la región en décadas anteriores y que se caracterizaba por la aplicación de una serie de medidas de política económica que apuntaban a la reducción del Estado, la entrega a manos privadas de servicios púbicos y de sectores económicos estratégicos y la apertura comercial indiscriminada, como parte del recetario neoliberal definido por el Consenso de Washington.

Entre los cambios introducidos por los gobiernos post-neoliberales a lo largo de estos últimos años destacan los esfuerzos por construir un regionalismo distante al modelo vigente durante el apogeo del neoliberalismo y que implicaba la incontrastable dominación de los Estados Unidos sobre el destino de los países de América Latina y el Caribe. Una de las manifestaciones más sobresalientes en esta dirección es la creación de instituciones regionales autónomas frente a Estados Unidos: la Alianza Bolivariana para los Pueblos de Nuestra América -ALBA-TCP- (2004), la Unión de Naciones del Sur-UNASUR- (2008), la Comunidad de Estados Latinoamericanos y Caribeños -CELAC- (2011) y el propio MERCOSUR (Mercado Común del Sur) que, constituido en 1991, fue relanzado en el año 2000 .

Las nuevas instituciones creadas, al contrario de lo sucedido en el pasado, han incorporado en sus agendas preocupaciones que van más allá de los aspectos comerciales, llamando por ejemplo la atención sobre políticas sociales o culturales, así como subrayando la vocación de paz de América Latina y el Caribe. No obstante, quedan aún varios desafíos pendientes como la construcción y puesta en marcha de políticas comunes en materia laboral o social, la elaboración de posturas regionales frente a temas de profundo impacto social y económico como el comercio ilícito de drogas; mayores compromisos y realizaciones concretas en torno a la nueva arquitectura financiera regional, precisiones respecto al abordaje de la dimensión ambiental en relación con las amenazas y potencialidades regionales; y, la discusión de una planificación productiva que considere las aptitudes y recursos de los diferentes países, para citar algunos de los temas que ameritan profundizarse.

Entre las asignaturas que tienen pendientes las nuevas instituciones regionales destacan el tratamiento de las fronteras y la libre movilidad de la población ${ }^{9}$. Estas temáticas no solo que tienen un peso marginal en relación con otros aspectos que concitan su atención, sino que en la práctica, las declaraciones y acuerdos en torno a la integración fronteriza o la movilidad humana, superan ampliamente la implementación de medidas y políticas concretas.

\footnotetext{
${ }^{9}$ Aunque el análisis del nuevo regionalismo efectuado en este estudio no se extiende al MERCOSUR, cabe destacar que el "Acuerdo sobre Residencia para Nacionales de los Estados Partes del MERCOSUR, Bolivia y Chile" (2002), al que adhirieron Perú (28 de junio de 2011), Ecuador (29 de junio de 2011) y Colombia (29 de junio de 2012), representa un significativo avance en materia migratoria en la medida en que simplifica los trámites y procedimientos para la obtención de permisos de residencia bianuales y permanentes y garantiza igualdad de libertades y derechos laborales y de educación para los y las inmigrantes y sus familias.
} 
Las escasas referencias a las fronteras en los planteamientos y orientaciones políticas de UNASUR, CELAC y ALBA, se circunscriben a ámbitos ligados con la seguridad y la defensa, al tiempo que resalta un abordaje limitado de los temas relacionados con la movilidad de las personas, asunto estrechamente vinculado a las áreas fronterizas. Un repaso de las posiciones de estos tres organismos alrededor de fronteras y movilidad humana corroboran esta afirmación.

Entre los objetivos específicos de UNASUR consignados en su Tratado Constitutivo, solo los numerales (i) y (k) contemplados en el artículo 3 guardan relación con la libre movilidad de las personas:

“(i) La consolidación de una identidad suramericana a través del reconocimiento progresivo de derechos a los nacionales de un Estado Miembro residentes en cualquiera de los otros Estados Miembros, con el fin de alcanzar una ciudadanía suramericana.

(k) La cooperación en materia de migración, con un enfoque integral, bajo el respeto irrestricto de los derechos humanos y laborales para la regularización migratoria y la armonización de políticas" (UNASUR, 2014).

A lo señalado en el Tratado Constitutivo respecto a la libre movilidad de las personas, la declaración de los jefes y jefas de Estado y de gobierno de UNASUR formulada en diciembre del 2014 se añade la aprobación del concepto de ciudadanía suramericana que facultaría a que todo ciudadano o ciudadana suramericana pueda optar por la visa de residente para trabajar, pueda ejercer su derecho a homologar los títulos, el derecho a tener la protección consular y a una protección efectiva. La meta final sería avanzar hacia la consecución de un pasaporte suramericano. El consenso al respecto dio paso a que jefas y jefes de Estado autoricen continuar con el proceso que facilite su implementación, el mismo que estaría a cargo del Grupo de Trabajo sobre Ciudadanía Suramericana.

Con relación a las fronteras, los "Procedimientos de Aplicación para las Medidas de Fomento de la Confianza y Seguridad" adoptado por los Ministros de Relaciones Exteriores y Defensa de UNASUR en Guayaquil en el año 2010 (CDS, 2010), establecen el intercambio de información respecto a las actividades militares intra y extrarregionales que ejecuten los Estados miembros, especialmente en áreas fronterizas, la implementación de medidas de seguridad para vigilar las fronteras, así como la coordinación de las actividades con miras a aumentar la eficiencia del control y vigilancia en las zonas de frontera y la prevención y represión a ilícitos transnacionales. Las medidas de fomento de la confianza advierten, además, sobre el respeto a la inviolabilidad territorial y la no intervención y operan como resguardo de aquellos acuerdos de cooperación en materia de defensa suscritos por cualquier Estado miembro de UNASUR y que eventualmente podrían ser utilizados como pretexto para actuar sobre el territorio de otro país. En esa dirección, las medidas de fomento de la confianza establecen un conjunto de garantías y prohibiciones para atentar contra la soberanía, la seguridad, la estabilidad y la integridad territorial de los demás Estados. Cabe recordar que en gran parte, este conjunto de alertas y compromisos fueron motivados como una reacción colectiva al bombardeo que efectúo Colombia sobre territorio ecuatoriano en la provincia de Sucumbíos, en el sitio conocido como Angostura, el 1 de marzo del 2008.

La coordinación de actividades militares intra y extrarregionales referidas a las 
fronteras incluye notificar de manera oportuna a los países limítrofes y a la UNASUR sobre cualquier maniobra, despliegue o ejercicio militar, terrestre, aéreo o naval planificado o no planificado que se realice en las zonas fronterizas. La información proporcionada debe contemplar el número de efectivos, la ubicación respecto a las fronteras, la naturaleza y cantidad de equipo que se utilizará (Ibid.).

La CELAC, por su parte, estableció en la Declaración de la Habana suscrita en la II Cumbre del año 2014, el compromiso de los Estados miembros por

"continuar consolidando sólidos principios regionales en materia de reconocimiento de los derechos de los migrantes, así como a profundizar la coordinación de políticas migratorias regionales y de posiciones comunes en las negociaciones globales e interregionales sobre migraciones, y en especial, en la promoción del debate internacional sobre el nexo entre la migración, el desarrollo y los derechos humanos" (numeral 26).

Este compromiso se sustenta en la posición de considerar a los migrantes como sujetos de derechos y en la intencionalidad de articular una posición común de cara a los procesos de diálogo con otros países e instituciones de alcance regional o global, manifestando su preocupación por los desafíos de la migración masiva, según consta en el plan de acción aprobado en octubre del 2012 en Santiago de Chile, así como en la "Declaración Especial sobre la Regularización Migratoria", suscrita en la Habana en 2014.

En lo concerniente a las fronteras, la CELAC ha consignado su intención de avanzar en acciones para fortalecer la infraestructura para la integración física del transporte, las telecomunicaciones y la integración fronteriza. Aunque, como se conoce, el estatuto de la CELAC es el de un mecanismo de diálogo, sin facultades para la exigencia del cumplimiento de sus decisiones, en la actualidad constituye un interlocutor de importancia para el diálogo con otras regiones del mundo y porque, a diferencia de otros espacios regionales, aglutina a un conjunto de países que comparten una historia común y desafíos similares.

Dentro de los cuatro ejes de trabajo priorizados por el ALBA-TCP, social, político, movimientos sociales y económico, son puntuales las referencias a la situación de las fronteras o la movilidad humana. Respecto a las fronteras, dentro del "Plan de Acción para el desarrollo del comercio en la zona económica de desarrollo compartido del ALBA-TCP" definido en Cochabamba en el año 2009, se señala, bajo el título IV, "Eliminación de barreras que obstaculicen la complementación", "la coordinación entre los diferentes organismos que intervienen en los controles de las mercancías en frontera, para que cooperen entre sí y coordinen sus procedimientos, evitando se constituyan en obstáculos innecesarios al comercio" (numeral 2).

El derecho a la libre movilidad de las personas, como base para fortalecer los lazos de hermandad entre todos los países del mundo, está presente en la declaración de los principios que rigen al Tratado de Comercio de los Pueblos (TCP) y en el documento elaborado por los países ALBA a propósito de la V Cumbre de las Américas, en el que se señala que "para que haya integración tiene que haber libre circulación de las personas, y derechos humanos por igual para todos sin importar su estatus migratorio" (ALBA-TCP, 2013: 94). 
La revisión de las orientaciones y planteamientos de las tres entidades regionales antes señaladas, UNASUR, CELAC y ALBA-TCP, permite concluir que el tratamiento de las fronteras no constituye una prioridad para el nuevo regionalismo latinoamericano. Además de identificar menciones escuetas y sueltas, no es posible desprender un posicionamiento claro y consistente al respecto. El contenido de los planteamientos de estas tres nuevas entidades regionales sugiere que sigue primando un enfoque de seguridad para las fronteras centrado alrededor de cooperación en materia militar, acciones de vigilancia e intercambio de información, control del contrabando y adopción de otras políticas nacionales o bilaterales que se concretan en una mayor presencia de las fuerzas de seguridad en las fronteras.

El énfasis en la seguridad y el control alrededor del manejo de las fronteras, apunta a consolidar el espacio estatal y a poner en marcha un conjunto de procedimientos que facilitan el establecimiento de distinciones sociales, culturales y políticas entre grupos humanos en una clara tensión con las declaraciones respecto a la ciudadanía suramericana y el fomento a la libre movilidad de las personas. Las fronteras se asimilan a mecanismos de control, sin considerar programas y medidas específicas para su integración, no desde un sitial subordinado, sino desde el interés por atender la realidad que atraviesa la población fronteriza.

En esta dirección, sobresale la contundencia con la que los gobiernos están aplicando medidas para frenar el contrabando en las fronteras o las disposiciones respecto a la propiedad en zonas fronterizas. En el primer caso cabe por ejemplo citar la experiencia de Brasil analizada por Cardin (2014). A través de un estudio comparativo este autor analiza la forma en cómo el régimen neoliberal de Fernando H. Cardoso y del Partido de los Trabajadores (PT) bajo la dirección de Lula enfrentaron el combate al contrabando. Durante el régimen de Cardoso, el control aduanero habría sido casi inexistente, mientras que con Lula, la mayor presencia del Estado en las diferentes dimensiones de la vida social, habría determinado la aplicación de una política más rigurosa de control y fiscalización. Según detalla Cardin, el mayor control durante este último gobierno habría venido de la mano con un conjunto de medidas para incidir sobre la pobreza como la renta mínima, la cualificación laboral y la escolarización. La perspectiva dominante dentro de la propuesta del PT era que las políticas sociales complementarias se desarrollasen de manera paralela a un conjunto de operaciones policiales orientadas a desmantelar cualquier tentativa de organización y mantención de la población por medios diferentes de aquellos fijados por el Estado.

Alrededor de las disposiciones sobre propiedad en las zonas fronterizas, merece traerse a colación la propuesta de Ley Orgánica de Fronteras formulada por el gobierno de Hugo Chávez en el año 2003 que no ha podido hasta el momento ser aprobada por las reacciones de varios colectivos que rechazaron algunos de sus enfoques. Entre los temas motivo de preocupación sobresalen la llamada "franja productiva" (Título X, Capítulo I) y el trato favorable hacia los militares: "Artículo 53: Con el objeto de impermeabilizar, generar empleos posterior al servicio militar a nuestros reservistas, poblar y desarrollar nuestras fronteras, se creará dentro de la Franja de Seguridad Fronteriza la franja productiva no menor de dos (2) kilómetros a lo largo de las fronteras colindantes y terrestres en la que funcionarán las unidades de producción". Según la ley, mientras más de once reservistas pueden constituir cooperativas (art. 54), a los reservistas individualmente se le puede asignar una parcela no mayor a 100 hectáreas (art. 55). Para no limitar el desarrollo de los caseríos, pueblos y ciudades colindantes a la franja productiva, el artículo 58 señala que "la Zona de Exención será de un metro en ambos sentidos por cada habitante del caserío, pueblo o 
ciudad, en ningún caso será menos de dos mil (2.000) metros ni más de veinte mil (20.000) metros por cada lado".

Junto al fortalecimiento de los esquemas de seguridad en torno a las fronteras, los países de la región han otorgado una particular importancia a la construcción de infraestructura regional para fortalecer la integración física entre los países de modo de facilitar la circulación de los productos y su conexión con los mercados internacionales a través de la ejecución de la Iniciativa de Infraestructura Regional Suramericana, ahora COSIPLAN-IIRSA y el Plan Puebla Panamá (PPP), ahora Proyecto Mesoamericano.

La IIRSA fue concebida por el Banco Interamericano de Desarrollo (BID) con la intención de desarrollar e integrar las infraestructuras de transporte, energía y telecomunicaciones para consolidar la orientación exportadora de las economías latinoamericanas; fue un activo promotor del ALCA (Área de Comercio de las Américas) y ha estado estrechamente vinculado al Plan Puebla Panamá y al Plan Colombia. Su énfasis en los mercados internacionales, antes que en la integración regional o el mejoramiento de las condiciones de vida de la población, explican que la satisfacción de las necesidades sociales, el fortalecimiento de empresas pequeñas y medianas y de cooperativas, la formulación de políticas que favorezcan la producción campesina, a las comunidades indígenas y a los productores independientes, no sean consideradas dentro de su alcance. Desde esta lógica, el quehacer de COSIPLAN-IIRSA respecto a las prácticas de fronterización radica en el fortalecimiento de la cooperación económica y transfronteriza, sin otorgar mayor atención a los efectos ambientales, a los crecientes movimientos migratorios o a los impactos culturales y sociales.

Ambas iniciativas persiguen la construcción de infraestructura física y favorecer cambios en las legislaciones, normas y reglamentos nacionales con el objeto de incrementar el comercio regional y global. Son, por tanto, como los califica Esther Ceceña (2013: 51), proyectos de reorganización territorial con miras a una amplia apertura hacia el mercado mundial y la expansión de la producción energética para sustentar el ritmo de crecimiento del continente.

Desde el 2000, la importancia concedida por los presidentes de América del Sur a la integración regional determinó que la región acoja como suya a la Iniciativa de Infraestructura Regional Suramericana. En el 2009, un año después de constituida la UNASUR, los presidentes suramericanos decidieron la creación de una instancia a la que se encargaría "implementar la integración de la infraestructura regional de los países Miembros de la UNASUR": el Consejo Suramericano de Infraestructura y Planeamiento (COSIPLAN) (UNASUR-COSIPLAN, 2013: 17). Los objetivos de COSIPLAN son "aumentar la competitividad de las economías de la región; contribuir a la reducción de las disparidades regionales y la desigualdad social y mejorar la calidad y expectativa de vida en cada país y en la región como un todo" (Ibid.: 19).

La cartera de proyectos del COSIPLAN crece cada año. Entre 2004 y 2014 el número de proyectos aumentó en más del 72\%. En efecto, de 335 proyectos en el año 2004, se pasó a 579 proyectos en el 2014. De los 579 proyectos definidos para el 2014, 179 están en ejecución, 137 proyectos están a nivel de perfil, 157 se encuentran en etapa de preejecución y 106 proyectos han concluido, comprometiendo recursos por 20.354,8 millones de dólares. Para esos mismos años la inversión total estimada se incrementó en más de 
cuatro veces, pasando de 37.424,8 millones de dólares en 2004 a 163.324,5 millones de dólares diez años después (UNASUR-COSIPLAN, 2014: 10).

La ejecución de los proyectos de IIRSA-COSIPLAN supone la construcción de grandes obras de infraestructura especialmente carreteras y demás facilidades para la operación de una ruta multimodal, puertos fluviales, aeropuertos, centros de almacenaje, centrales hidroeléctricas, puentes, túneles, redes ferroviarias, etc. y el establecimiento de industrias a lo largo del territorio, atravesando áreas de particular valor ecológico ${ }^{10} \mathrm{y}$ territorios habitados históricamente por pueblos indios, algunos de quienes han decidido vivir en condiciones de aislamiento voluntario; favoreciendo patrones de colonización escasamente planificados, el incremento de la extracción ilegal de madera, la expansión de la frontera agrícola y de los monocultivos; la alteración y contaminación de ríos y una compleja re-organización del territorio.

Diversos análisis respecto a los probables impactos de la IIRSA (Ceceña, Aguilar y Motto, 2007; Bonilla, 2010) advierten no solo de los pasivos sociales y ambientales de una propuesta de infraestructura tan ambiciosa, sino que señalan los límites para que esta efectivamente contribuya al crecimiento económico del conjunto de los países de la región. Las diferencias en materia de desarrollo tecnológico, capacidades instaladas y movilidad de capitales podrían determinar que la mayor parte de los países sea considerado solo como lugar de paso y circulación, que sus territorios sirvan como soporte para la instalación y operación de empresas maquiladoras o que probablemente se articulen a la IIRSA a través de las mismas o nuevas actividades económicas primarias. En cualquier caso, esas actividades contarán con una alta participación de capital foráneo asociado a capitales nacionales (estatal o público), con el riesgo de mermar la soberanía debido a que las decisiones sobre estos territorios estarán sujetas a los intereses de los inversionistas y de las compañías que operen a lo largo del eje (Bonilla, 2010: 7). Algunas de las obras, que atravesarán territorios ancestrales, obligarán a la reubicación de sus poblaciones, mientras que la construcción de infraestructura y la instalación de actividades económicas, probablemente motiven una mayor presencia militar en el área.

A la luz de las consecuencias que podrían derivarse, si la IIRSA mantiene la misma orientación que le otorgó el BID en su nacimiento, el nuevo regionalismo latinoamericano estaría generando una fuerte tensión entre la búsqueda de autonomía y la continuidad de políticas que no han reparado en el bienestar de la población fronteriza ni han superado el tratamiento de las fronteras como áreas subalternizadas.

\section{¿Es nueva la seguridad en el nuevo regionalismo estratégico?}

La primera doctrina de política exterior de los Estados Unidos, la misma que sentó las bases de la seguridad regional, fue la Doctrina Monroe (1823), promulgada un año antes de la Batalla de Ayacucho, que puso fin a la colonización española en América del Sur. Su creador, John Quincy Adams, Secretario de Estado, advirtió en su lanzamiento: "Estados Unidos no tiene amistades permanentes, tiene objetivos e intereses permanentes", de ahí

\footnotetext{
${ }^{10}$ Con el ánimo de graficar la magnitud y envergadura de los impactos cabe citar el caso del eje multimodal Manta-Manaos, contenido en la IIRSA, concebido como un corredor de transporte que conectará áreas del Pacífico, desde Manta en Ecuador, hasta el Atlántico, en Manaos, Brasil. En su trayecto por Ecuador afectará la Reserva Biológica Limoncocha, el Parque Nacional Llanganates, el Parque Nacional Yasuní, la Reserva Cuyabeno, el Parque Nacional Gran Sumaco y el Napo Galeras (Bonilla, 2010).
} 
estableció la conocida fórmula "América para los americanos" (Boron, 2013: 64). Theodore Roosevelt profundizó la Doctrina Monroe en 1904 "al establecer que si un país de las Américas amenazaba o atacaba la propiedad de ciudadanos o empresas estadounidenses o cercenaba sus derechos, Washington se vería obligado a intervenir en los asuntos internos del país en cuestión para restablecer el orden y el imperio de la ley" (Ibid.: 65). Como sostiene Van Klaveren, la Doctrina Monroe "constituyó una suerte de declaración preventiva que marcó el comienzo de la delimitación del Hemisferio Occidental como una zona de influencia exclusiva de los Estados Unidos, delimitación que asumió el carácter de un proceso gradual y acumulativo" (1983: 121).

A partir de esta postura, Estados Unidos se concentró en la difusión y aplicación de la Doctrina de Seguridad Nacional, que no solo sirvió de fundamento ideológico de las dictaduras militares que gobernaron varios países latinoamericanos desde mediados de la década de 1960 hasta los años 80 del siglo pasado, sino que sustentó su supuesto derecho a intervenir en cualquier lugar donde considere afectados sus intereses o de sus empresas privadas, a justificar las agresiones contra otros pueblos y a expandir su poder hacia cualquier punto de la geografía planetaria.

La presencia de la Unión Soviética y de Cuba en América, justificaron la prolongación de esta doctrina y su articulación con nuevos elementos. Desde 1980 en adelante, y sobre la base de la definición del "narcotráfico" como un peligro para "la seguridad nacional" de Estados Unidos, Reagan presionó a los gobiernos de Bolivia, Perú y Colombia, afines a su política, a emprender lo que posteriormente se conocería como la "guerra contra las drogas" (Suárez, 2003).

Una vez disuelta la Unión Soviética (1991), el enfoque de la seguridad se volcó al control de las amenazas internas y externas consideradas como todas aquellas fuerzas que pudieran atentar contra la democracia, la estabilidad o la seguridad de los recursos naturales estratégicos de los Estados, al tiempo que se atestiguó el aparecimiento de nuevos modelos geopolíticos. En la ausencia de confrontaciones reales, para justificar la centralidad de la seguridad, fuertemente asimilada a la noción de defensa, se elaboró un sofisticado andamiaje conceptual, tanto en los ámbitos multilaterales, como al interior de los países, orientado a matizar las políticas de seguridad bajo diversos calificativos: seguridad humana, seguridad ciudadana, seguridad democrática, seguridad integral, seguridad cooperativa (Garzón, 2012).

Contando en la región con gobiernos dóciles a sus políticas, Estados Unidos optó por concentrar lo fundamental de su atención en los países del golfo pérsico y en sus importantes reservas de petróleo y gas. Los atentados que sufrió la ciudad de Nueva York en el 2001 justificaron la invasión sobre Irak que más tarde se extendería a otros países vecinos, así como el lanzamiento de la nueva Estrategia de Seguridad Nacional de Estados Unidos, en la que el Presidente George W. Bush proclamó el supuesto derecho de ese país a emprender "guerras preventivas" contra aquellos Estados del mundo que amenazaran los intereses de su país y de sus amigos.

Durante el período de disputa geopolítica para posicionar los intereses estadounidenses en los países del oriente medio, la principal herramienta de control que utilizó Estados Unidos en América Latina fue el Plan Colombia, a lo que añadió una fuerte presión por avanzar en la firma de acuerdos de libre comercio (que circunstancialmente se detuvieron luego de la oposición expresada por los países latinoamericanos al ALCA en Mar del Plata en 2005) y la adopción de acuerdos de seguridad subregionales como la Alianza 
para la Seguridad y la Prosperidad de América del Norte, ASPAN, pacto establecido en 2005 entre los gobiernos de Estados Unidos, México y Canadá. Este último sirvió a su vez de marco para el lanzamiento de la Iniciativa Mérida (Plan México) y la Iniciativa de Seguridad Regional de Centro América (CARSI), ambos en el 2008, y de la Iniciativa de Seguridad de la Cuenca del Caribe (CBSI) en el año 2010 (Ceceña, 2013: 52).

El Plan Colombia, una estrategia militar y de control territorial, disfrazada de una política de desarrollo, se firmó durante los gobiernos de Andrés Pastrana (1998-2002) y Bill Clinton (1993-2001). En lo económico, el Plan Colombia ha supuesto la canalización de un cuantioso flujo de recursos proveniente de los Estados Unidos. La asistencia militar y policial hacia Colombia superó los siete mil millones de dólares en el período 1996-2014, lo que convierte a este país en el mayor destinatario de asistencia militar estadounidense en la región. México, que le sigue, ha recibido en el período citado y por el mismo concepto un poco menos de la tercera parte del financiamiento percibido por Colombia (Isacson, Haugaard, Poe et al. 2013: 20).

Tras las derrotas sufridas en Irak, Afganistán y Libia, y de la mayor presencia que adquirieron en América Latina países como Rusia, China, Irán, India y Francia alrededor de la venta de armamentos y el desarrollo de inversiones en sectores estratégicos, Estados Unidos está seriamente interesado en reconstruir su hegemonía en la región. De ahí que a partir de la segunda mitad de la primera década de este siglo, su presencia militar haya adquirido proporciones cada vez más crecientes y preocupantes: mientras en el año 2007, disponía de 17 bases militares en América Latina y el Caribe, en la actualidad su número se aproxima a $80^{11}$, junto con el despliegue desde el año 2008 de la IV Flota y la presencia de personal militar de Estados Unidos en América Latina. La magnitud de este despliegue explica, según Saxe-Fernández (2009), el interés por concretar la ocupación militar en la porción norte y sur de América Latina y reafirma la supremacía concedida por Estados Unidos a las riquezas naturales que contiene la región, o para decirlo en palabras de Boron:

"La idea subyacente a la instalación de bases militares -o la autorización para usar las existentes en la región- es la crear 'capas envolventes' con capacidad de controlar el acceso y los modos de uso y de explotación de los territorios y, a la vez, neutralizar las iniciativas que pudieran impulsar los movimientos sociales y fuerzas políticas opuestas a las políticas de 'desposesión' promovidas por el capital”' (2013: 170-171).

Frente a esta realidad, ¿cuál ha sido la respuesta del nuevo regionalismo?, ¿qué cambios se han introducido y cuáles son las rupturas con respecto a la estrategia de dominación militar y de seguridad que promueve Estados Unidos?

En materia de defensa y seguridad, el Tratado Constitutivo de UNASUR suscrito en Bogotá en mayo del 2008 y puesto en vigor en marzo del 2011, si bien incorpora la oposición de Suramérica a las armas nucleares y de destrucción masiva, no entraña una declaración de ruptura o de cambios relevantes con la visión de seguridad y defensa impuesta por Estados Unidos. En lo sustantivo, los aspectos relativos a defensa y seguridad

\footnotetext{
${ }^{11}$ Ana Esther Ceceña contabiliza un total de 85 bases en el 2013 (39 bases fijas y 46 buques artillados considerados como bases itinerantes) (2013: 155). En el texto de Atilio Boron, "América Latina en la Geopolítica del imperialismo", el autor cita a Telma Luzzani quien estima que existen 72 bases militares norteamericanas (o de países de la OTAN, o de la OTAN, pero controladas por Estados Unidos) y a Rina Bertaccini cuyos cálculos hablan de 75 bases (2013: 172).
} 
permanecen atados a los ámbitos que al respecto han sido priorizados por Estados Unidos, según se desprende de los literales correspondientes a esta temática que constan en el Artículo 3:

“(q) La coordinación entre los organismos especializados de los Estados Miembros, teniendo en cuenta las normas internacionales, para fortalecer la lucha contra el terrorismo, la corrupción, el problema mundial de las drogas, la trata de personas, el tráfico de armas pequeñas y ligeras, el crimen organizado transnacional y otras amenazas, así como para el desarme, la no proliferación de armas nucleares y de destrucción masiva, y el desminado;

(s) El intercambio de información y de experiencias en materia de defensa;

(t) La cooperación para el fortalecimiento de la seguridad ciudadana." (UNASUR, 2014).

A nivel regional, el avance más significativo para tomar distancia con respecto a la estrategia militar de Estados Unidos es la conformación del Consejo de Defensa Suramericano (CDS), creado en diciembre del 2008, poco después de que Estados Unidos decidiera reactivar la IV Flota. Entre los principios más sobresalientes del CDS destacan el respeto de manera irrestricta a la soberanía, integridad e inviolabilidad territorial de los Estados, la no intervención en sus asuntos internos y la autodeterminación de los pueblos; la promoción de la paz y la solución pacífica de controversias; la preservación $\mathrm{y}$ fortalecimiento de Suramérica como un espacio libre de armas nucleares y de destrucción masiva, promoviendo el desarme y una cultura de paz en el mundo; el fomento de la defensa soberana de los recursos naturales de nuestras naciones; la promoción de la responsabilidad y la participación ciudadana en los temas de la defensa, en cuanto bien público que atañe al conjunto de la sociedad (Artículo 3) (UNASUR, 2008).

Los objetivos del CDS comprenden la consolidación de Suramérica como una zona de paz; la construcción de una identidad suramericana en materia de defensa y el fortalecimiento de la cooperación regional en este ámbito (Artículo 4). A estos se suman objetivos específicos orientados a la construcción de una visión conjunta alrededor de la defensa; el intercambio de información; el intercambio y la cooperación en el ámbito de la industria de la defensa y en la formación y capacitación; la adopción de medidas de confianza, y la incorporación de la perspectiva de género en el sector de la defensa (Artículo $5)$.

No deja de tener una relevancia ética y política la "Declaración sobre Suramérica como zona de Paz" adoptada durante la IV Reunión Ordinaria de UNASUR, llevada a cabo en Lima en el año 2012. Si bien tal Declaración debe concretarse en la formulación de un Protocolo de Paz, Seguridad y Cooperación, sus contenidos reafirmaron la posición expresada por los y las presidentes de América del Sur en Guayaquil, Ecuador, en el 2002, cuando se declaró a Suramérica como zona de paz y cooperación.

Llama la atención que el Estatuto del Consejo de Defensa Suramericano en su artículo 2 señale que éste se sujetará a los principios y propósitos establecidos en la Carta de las Naciones Unidas y en la Carta de la Organización de Estados Americanos. La sujeción a esta última entidad implica, finalmente, aceptar el papel de organismos como el Tratado Interamericano de Asistencia Recíproca (TIAR) o la Junta de Defensa Interamericana y 
plantea un interrogante respecto a los continuos cuestionamientos expresados por presidentes de América Latina en torno a la legitimidad de la OEA y sus organismos. Cabe recordar al respecto el discurso del Presidente ecuatoriano Rafael Correa durante la cuadragésima segunda Asamblea de la OEA celebrada en el 2012, del cual sobresalen algunos extractos:

"Estamos transformando nuestras democracias de plastilina en democracias reales. Todas las instancias de nuestra Américas deben estar en función de este cambio de época. Revolucionarse o desaparecer, entendiendo que las instituciones no son fines, sino los medios para lograr el buen vivir de nuestros pueblos.

(...)

Lamentablemente vemos que el sistema interamericano no está al nivel de este cambio de época, sin poder dar soluciones o al menos posturas contundentes y decisivas a problemas tales como las colonias en Nuestra América. Me refiero a las Islas Malvinas o al embargo criminal que sufre ya por medio siglo un país hermano como Cuba o cosas tan sencillas como llevar ante la justicia a los responsables del golpe de Estado en contra del Presidente Manuel Zelaya.

Históricamente la OEA ha servido como instrumento de política internacional de países hegemónicos.

(...)

La crisis, la falta de representatividad también la podemos ver en el Sistema Interamericano de Derechos Humanos y, particularmente, en la Comisión Interamericana de Derechos Humanos, la cual está totalmente influenciada e incluso dominada por países hegemónicos, por el 'oenegismo'. Tendrán dificultad de traducir este término es un neologismo, para describir esa influencia desproporcionada, muchas veces ilegítimas, de las ONGs, organizaciones no gubernamentales, influencia que (...) se está convirtiendo en un problema serio para nuestros sistemas democráticos" $" 12$.

La CELAC formuló declaraciones similares a las de UNASUR. En el 2014, a través de la "Proclama de América Latina y el Caribe como Zona de Paz", los países integrantes de este foro político reafirmaron el respeto de los principios y normas del Derecho Internacional, el compromiso de solución pacífica de las controversias, la obligación de los Estados de no intervenir en los asuntos internos de otro Estado; la observancia de los principios de soberanía nacional, la igualdad de derechos y libre determinación de los pueblos; el principio de la tolerancia y de vivir en paz; el respeto del derecho inalienable de todo Estado a elegir su sistema político, económico, social y cultural y el compromiso de continuar promoviendo el desarme nuclear como objetivo prioritario y contribuir con el desarme general y completo, para propiciar el fortalecimiento de la confianza entre las naciones. Esta proclama se complementa con la formulación, en el mismo año, de la declaración sobre desarme nuclear.

\footnotetext{
${ }^{12}$ El texto completo del discurso puede encontrarse en https://cesaraching.wordpress.com/2012/06/09/texto-del-discurso-del-presidente-rafael-correa-enecuador-en-la-oea-video/. Consulta realizada el 25 de enero de 2016.
} 
Los pronunciamientos más radicales en torno a la seguridad y defensa han surgido en el seno del ALBA-TCP que en la Declaración Conjunta de la VIII Cumbre, que tuvo lugar en Cuba en 2009, recalcó que América Latina y el Caribe debe ser una región libre de bases militares extranjeras y calificó de inaceptable utilizar la lucha contra el tráfico de drogas y el terrorismo internacional como pretexto para el incremento de la presencia militar norteamericana en la región. En esta misma Declaración, el ALBA - TCP insistió ante el gobierno de Colombia, de la misma manera que lo hizo durante su VII Cumbre en el año 2009 en Cochabamba, a reconsiderar la instalación de bases militares establecidas en el marco del Acuerdo para la Cooperación y Asistencia Técnica en Defensa y Seguridad con los Estados Unidos (ALBA-TCP, 2013).

Entre las respuestas nacionales, resulta emblemática la decisión adoptada por Ecuador en ese mismo año, consistente en no renovar el acuerdo sobre la base militar de Manta que operaba en la provincia ecuatoriana de Manabí hace más de una década como un apoyo del gobierno ecuatoriano para que el Ejército de Estados Unidos realice actividades de control del narcotráfico en el Pacífico. A la decisión de no renovación del acuerdo le precedió el bombardeo realizado por el ejército colombiano en territorio ecuatoriano (Angostura, provincia de Sucumbíos) el 1 de marzo del 2008, acción sobre la que existían indicios de involucramiento del personal y equipo aéreo estadounidense estacionado en la base de Manta.

En el ámbito de las declaraciones y su impacto sobre las fronteras, resulta valioso reconocer la importancia concedida por el nuevo regionalismo a los principios de respeto a la soberanía, integridad e inviolabilidad territorial de los Estados, así como el compromiso entre los Estados de no recurrir a la amenaza o uso de la fuerza o cualquier tipo de agresión militar o riesgos hacia la estabilidad, la soberanía y la integridad territorial de los Estados miembros. Tales posturas, como se ha señalado, son explícitas en UNASUR, ALBA-TCP y CELAC.

El discurso de seguridad del nuevo regionalismo no ha podido sin embargo, contrarrestar la influencia de la política de defensa de los Estados Unidos. La presión estadounidense ha alentado la homologación de criterios entre las Fuerzas Armadas de la región, así como la adopción de códigos civiles que criminalizan las acciones sociales y leyes antiterroristas, sin perder de vista que muchos países de la región continúan apoyándose en la formación militar entregada por instituciones de Estados Unidos como el Instituto Hemisferio Occidental para la Cooperación de Seguridad Western Hemisphere Institute for Security Cooperation (WHISC) (nombre que adoptó desde el año 2001 la Escuela de las Américas fundada en 1946). Entre 2009 y 2013, cerca de 22 mil policías y militares de varios países latinoamericanos (México, Guatemala, Honduras, El Salvador, Costa Rica, Panamá, Ecuador, Perú) fueron formados en Colombia con el apoyo del Comando Sur de las Fuerzas Armadas estadounidenses (SOUTHCOM) (Suárez, 2014: 8). En la misma línea, resulta preocupante reconocer que el nuevo regionalismo tampoco haya podido detener la suscripción de iniciativas de seguridad subregionales, menos aún rechazar la instalación de bases militares en la región, y que todavía en 2013 y 2014 hayan subsistido vínculos entre las fuerzas armadas latinoamericanas con las agencias militares de Estados Unidos, como su participación en las actividades ejecutadas por la Junta Interamericana de Defensa o en las conferencias que cada dos años se celebran entre los ejércitos americanos, la Conferencia Naval Interamericana y el Sistema de Cooperación de las Fuerzas Aéreas Americanas (Ibid.: 23). 
En relación con las fuerzas armadas, el empeño por dotar de una dirección civil a los ministerios de defensa, cuyos resultados habría que evaluar con más detenimiento, y la promulgación de nuevas legislaciones son algunos de los cambios más notables introducidos en los últimos años. Como constantes, por el contrario, se mantiene un número de personal armado que cuantitativamente no se ha modificado en el período 2007-2012 ${ }^{13}$ y una estructura institucional que aún goza de una alta capacidad de incidencia en la realidad latinoamericana. Igualmente se ha popularizado, con consecuencias poco meditadas, como la militarización de las relaciones sociales y civiles, la incorporación de militares a la realización de actividades ajenas a su función (construcción de infraestructura, vigilancia de recursos estratégicos, apoyo a la policía y seguridad en las principales ciudades latinoamericanas). Tabla 1. Gasto militar como porcentaje del PIB en los países de América
del Sur (2005-2006)*

\begin{tabular}{|l|c|c|c|c|c|c|c|c|c|c|l|}
\hline \multicolumn{1}{|c|}{ País } & $\mathbf{2 0 0 5}$ & $\mathbf{2 0 0 6}$ & $\mathbf{2 0 0 7}$ & $\mathbf{2 0 0 8}$ & $\mathbf{2 0 0 9}$ & $\mathbf{2 0 1 0}$ & $\mathbf{2 0 1 1}$ & $\mathbf{2 0 1 2}$ & $\mathbf{2 0 1 3}$ & $\mathbf{2 0 1 4}$ & Evolución \\
\hline Argentina & 0,76 & 0,70 & 0,69 & 0,68 & 0,78 & 0,75 & 0,72 & 0,75 & 0,82 & 0,79 & \\
\hline Bolivia & 1,78 & 1,57 & 1,69 & 1,96 & 2,00 & 1,67 & 1,47 & 1,46 & 1,45 & 1,48 & \\
\hline Brasil & 1,52 & 1,48 & 1,47 & 1,44 & 1,54 & 1,54 & 1,41 & 1,41 & 1,38 & 1,34 & \\
\hline Chile & 2,41 & 2,41 & 2,29 & 2,53 & 2,19 & 2,16 & 2,17 & 2,06 & 1,94 & 1,99 & \\
\hline Colombia & 3,35 & 3,28 & 3,27 & 3,71 & 3,86 & 3,63 & 3,07 & 3,17 & 3,42 & 3,46 & \\
\hline Ecuador & 2,30 & 2,03 & 2,57 & 2,67 & 3,12 & 3,01 & 3,10 & 2,71 & 2,78 & 2,72 & \\
\hline Guyana & 2,24 & 1,31 & 1,43 & 1,59 & 1,53 & 1,38 & 1,26 & 1,18 & 1,18 & 1,24 & \\
\hline Paraguay & 0,94 & 1,05 & 1,00 & 0,96 & 1,11 & 1,08 & 1,20 & 1,38 & 1,36 & 1,46 & \\
\hline Perú & 1,53 & 1,39 & 1,20 & 1,14 & 1,42 & 1,32 & 1,19 & 1,23 & 1,47 & 1,38 & \\
\hline Uruguay & 2,08 & 2,06 & 1,84 & 1,95 & 2,05 & 1,96 & 1,76 & 1,76 & 1,86 & 1,59 & \\
\hline Venezuela & 1,41 & 1,63 & 1,29 & 1,37 & 1,22 & 0.85 & 0.75 & 1,30 & 1.43 & n.d. & \\
\hline
\end{tabular}

* No hay datos para Surinam

Fuente: http://datos.bancomundial.org/indicador/MS.MIL.XPND.GD.ZS, consulta realizada el 25/01/2015.

Elaboración: La autora

${ }^{13}$ Luego del crecimiento en el número de personal de las Fuerzas Armadas registrado entre los años 2005-2006, los ejércitos de América Latina, con excepción de Colombia, no han evidenciado crecimiento en términos de su composición numérica. Para el 2012, en América Latina 1.866.694 de hombres y mujeres pertenecían a las Fuerzas Armadas; cerca de la cuarta parte de este total (440.224) correspondía a las Fuerzas Armadas de Colombia (http://datos.bancomundial.org/indicador/MS.MIL.TOTL.P1?display=default). Consulta realizada el 05/11/2014. 
El peso e importancia concedidos a la seguridad y a la militarización de los países de América Latina se evidencia en los recursos económicos destinados para tales propósitos. Si bien entre los años 2005 y 2014 la relación gasto militar/PIB se ha mantenido relativamente estable en el conjunto de América del Sur, con diferencias en el comportamiento individual de los países ${ }^{14}$ (ver tabla 1), en términos absolutos, información de UNASUR señala que "en el lapso de 5 años, el gasto en defensa casi se duplicó, pasando de 17,65 mil millones de dólares en 2006 a 33,2 mil millones de dólares en 2010" (CDS, 2012).

La relativa estabilidad y en ciertos casos, el crecimiento en el gasto y equipamiento militar contrasta con la ausencia de conflictos limítrofes atribuibles a disputas territoriales o con la ocurrencia de atentados. De ahí que para explicar esta tendencia los gobiernos de la región hayan apelado a la necesidad de modernizar las Fuerzas Armadas, de actualizar equipamiento obsoleto y de garantizar la protección de su patrimonio natural, sin alejarse de la posturas que, desde Estados Unidos, han enfatizado en la necesidad de combatir el narcotráfico, el control de los cultivos de coca, y toda amenaza a la seguridad interna, lo que coloca al discurso de defensa de la región en una posición sino contradictoria, al menos ambigua y poco clara con respecto a las decisiones que en materia de defensa emanan desde Washington y el Pentágono.

Las tensiones entre un discurso que busca autonomía con respecto a Washington y el acatamiento de varias de sus disposiciones y medidas alrededor de los temas de seguridad y defensa, repercuten en el manejo de las fronteras a las que se considera áreas no solo delictivas, sino muchas veces permeadas por la amenaza terrorista, lo que justifica la puesta en marcha de procedimientos de extrema intimidación y control. No es el caso únicamente de las áreas fronterizas de Ecuador y Venezuela con Colombia donde el desbordamiento del conflicto colombiano podría explicar una mayor presencia militar; sucede también en la frontera amazónica que comparten Perú, Colombia y Brasil o en la llamada Triple Frontera entre Argentina, Paraguay y Brasil que en el imaginario social ha pasado de ser una zona donde las actividades delictivas representaban una amenaza a un área asociada con el peligro terrorista $^{15}$ (Giménez, 2011, citado por García Pinzón, 2014: 235).

\section{Repensando las fronteras y la seguridad}

Si bien la creación del Consejo de Defensa Suramericano es una respuesta soberana de los países de América del Sur por diferenciarse del marco institucional de defensa fijado unilateralmente por Estados Unidos, su existencia y funcionamiento enfrenta, en paralelo, contradicciones y tensiones motivadas por presiones internas y externas que fuerzan el mantenimiento de las políticas de seguridad y defensa vinculadas a las definiciones y énfasis fijados por Washington. La persistencia de anteriores prácticas en materia de seguridad y

\footnotetext{
${ }^{14}$ En el período 2005-2014, la proporción de gasto militar con respecto al PIB disminuye o se mantiene estable en ocho de los once países para los que se dispone de información y aumenta en cinco: Paraguay, Ecuador y Colombia, en su orden.

${ }^{15}$ Viviana García Pinzón da cuenta que después de los hechos del 11-S, la población islámica que vive en esta área fue sujeta a la vigilancia de los Estados Unidos como posible fuente de financiamiento de actividades terroristas. En los años inmediatamente posteriores, Paraguay, Brasil y Argentina implementaron medidas legales para restringir el flujo de divisas y en agosto de 2012, el gobierno brasilero puso en marcha la "Operación gata" mediante la que se movilizaron cerca de 9.000 efectivos de las Fuerzas Armadas a las fronteras con Argentina, Paraguay y Uruguay para combatir el tráfico de drogas, armas y el contrabando en general (2014: 240-241).
} 
defensa, así como la agudización de algunas de sus manifestaciones, relativizan el hecho de que las rupturas en este campo sean de la envergadura y profundidad que advierten los discursos.

El aumento paulatino del gasto en armamento, las legislación en torno a la seguridad y la defensa, la introducción de legislación antiterrorista en 33 países (Boron, 2013: 196), la vigencia de programas de formación de militares y policías en instituciones lideradas por los Estados Unidos y el funcionamiento de bases militares extranjeras en territorios soberanos, son algunos de los elementos que revelan la complejidad que enfrenta la región para desprenderse de la política guerrerista de los Estados Unidos y evidencian las tensiones que tales prácticas mantienen con un discurso nuevo que intenta surgir en la región en torno a la seguridad y la defensa. Para el caso de las fronteras, las contradicciones y tensiones resultan aún más contundentes. Ésta es un área poco explorada, normalmente circunscrita a la decisión unilateral de los gobiernos, sin considerar en el plano regional una visión de conjunto capaz de considerar programas concretos orientados a fomentar la integración de los territorios fronterizos y apoyar el desarrollo local de sus poblaciones, menos aún de incorporar la opinión y puntos de vista de las poblaciones de frontera.

Más allá de la retórica en torno a la participación, la tradición centralista de los Estados latinoamericanos ha marcado las pautas de las prácticas de fronterización en el manejo de las áreas fronterizas. De ahí que en los acuerdos y declaraciones surgidas a la luz del nuevo regionalismo latinoamericano se siga privilegiando la aplicación de esquemas de control y militarización de estos territorios ${ }^{16}$, una creciente presencia policial o el perfeccionamiento de los niveles de coordinación entre las llamadas fuerzas del orden de modo de mejorar la oportunidad de las intervenciones y la construcción de infraestructura como medio de integración por excelencia, omitiendo sus efectos sobre la desestructuración social y la degradación del ambiente. En los pronunciamientos del nuevo regionalismo no existen estrategias ni planteamientos concretos referidos a la integración social, productiva y cultural.

En el caso de la movilidad humana, parecería ser que en medio del dominio neoliberal vigente a escala planetaria, el nuevo regionalismo no ha podido escapar de nociones según las cuales las mercancías y los capitales tienen mayor libertad para traspasar las fronteras regionales que los seres humanos. Pese a que el enfrentamiento de este debate y la identificación de respuestas democráticas es de singular trascendencia para las poblaciones asentadas en las fronteras, aún no se concretan políticas y estrategias en el campo de la movilidad humana emanadas desde el nuevo regionalismo. Sin restar importancia a la reciente declaración de UNASUR en torno a su compromiso para avanzar en la obtención de una ciudadanía suramericana, vale recordar que esta aspiración está

\footnotetext{
${ }^{16}$ Aunque sin ser parte de un consenso regional, una mención particular podría entrañar "Plan Ecuador" como una respuesta de paz propuesta por Ecuador frente al Plan Colombia y sus efectos sobre la frontera norte ecuatoriana que, en su diseño, parecía ofrecer una respuesta alejada de las premisas convencionales en el tratamiento de las fronteras. Creado en el 2007 en medio de altas expectativas, su operación poco a poco fue bajando de perfil: desde una política estatal prioritaria, pasó a convertirse en una pequeña oficina dentro de la Secretaría Nacional de Planificación del Estado. El declive de la Secretaría Técnica de Plan Ecuador se sucedía de manera paralela a la entrega, a las Fuerzas Armadas, de la responsabilidad de construcción de escuelas, puentes o la realización de estudios específicos sobre la situación fronteriza. Sin el ánimo de plantear criterios evaluativos finales, lo que debería ser motivo de un esfuerzo particular, las políticas y enfoques de control, vigilancia y seguridad, pudieron finalmente eclipsar el alcance inicial de esta iniciativa.
} 
presente desde el 2006, con limitaciones para arribar a la definición de concreciones y medidas específicas.

En los más ambiciosos proyectos de infraestructura en marcha como la IIRSA en América del Sur o el Proyecto Mesoamericano, para el caso de México, los países de América Central, Colombia y República Dominicana, es notoria la ausencia de políticas o acciones relativas a la movilidad humana o la calidad de vida de las poblaciones fronterizas. La iniciativa IIRSA concentra su atención, al decir de Ceceña, Aguilar y Motto en el diseño de nuevas fronteras y regiones definidas por su "actividad industrial y concentración poblacional, es decir, por la fuerza de trabajo real y potencial que ofrecen, y el resto por las dádivas de la naturaleza, puesto que se trata de poner en ruta la explotación de yacimientos hidrocarburíferos, minerales, genéticos, acuáticos y también agropecuarios" (2007: 17). Resulta preocupante constatar que un proyecto de esta envergadura, generado en un contexto neoliberal de apertura indiscriminada haya sido retomado por el regionalismo postneoliberal sin introducir una reorientación en su concepción, marcando una continuidad con el pasado reciente bajo el pretexto de "aprovechar las ventajas ofrecidas por la globalización" (UNASUR-COSIPLAN, 2013: 19). La IIRSA antes que promover la integridad territorial, impulsa ordenamientos territoriales funcionales a la demanda externa de commodities y mercancías. La construcción de infraestructura no representa un beneficio directo para la población si de manera paralela no se revalorizan las fronteras como espacio de diálogo e interacción. Varios ejemplos en América Latina señalan que carreteras y puentes han contribuido a incrementar el comercio terrestre entre países a costa de la agudización del control y la represión sobre la circulación de las personas, de las pequeñas mercancías y de formas de subsistencia que históricamente se han mantenido entre las poblaciones fronterizas. El caso del puente que une la ciudad argentina de Posadas con la paraguaya de Encarnación, estudiado por Grimson (2005b), da cuenta de la afectación que percibieron las mujeres paraguayas -“paseras"-, que hace más de un siglo viven del comercio en pequeña escala, debido a los mayores controles aduaneros, generando conflictos y protestas locales que determinaron el involucramiento de los mandatarios de ambos países.

El contrabando y el comercio irregular son comunes en las regiones fronterizas y todo esfuerzo por disciplinar tales prácticas requeriría de un abordaje político que rebase el control y la represión en la medida en que su continuidad, si bien habla de las precarias condiciones de vida y la falta de oportunidades de trabajo, hacen también alusión a variables sociales y culturales cuyo peso pasa desapercibido.

Además de un recurso económico, estudios de caso llevados a cabo en regiones fronterizas advierten que la frontera es un espacio de generación de estrategias de ejercicio de ciudadanía de las poblaciones que viven entre dos Estados nacionales (Albuquerque, 2014). En el caso de la frontera ecuatoriana-colombiana era usual, hasta la segunda mitad de la década del 2000, que la población colombiana recurra a los establecimientos de salud ubicados en las ciudades y pueblos fronterizos del Ecuador, la compra de medicamentos en farmacias colombianas por parte de la población ecuatoriana, o la realización de llamadas por telefonía móvil desde el territorio colombiano hacia cualquier provincia del Ecuador, debido a los costos más bajos de este servicio en el vecino país.

Frente a los límites y vacíos identificados en relación al abordaje de las fronteras, los siguientes puntos tienen por objetivo proponer algunos elementos de debate y reflexión que contribuyan a transitar hacia un manejo fronterizo centrado en la gente y a ponderar de mejor manera el énfasis de seguridad que se ha asignado para su abordaje. 
Si bien no directamente vinculado a las fronteras, un primer elemento que merece discutirse por sus implicaciones en las áreas fronterizas, gira en torno a la necesidad de generar un discurso regional autónomo en relación con la seguridad y la defensa. No basta la creación de un organismo de coordinación en materia de defensa. El CDS, aunque importante, es insuficiente en miras a alcanzar la autonomía en relación a la política de defensa marcada por los Estados Unidos. La consecución de políticas soberanas y de autodeterminación en este campo supone, como lo señala Elsa Bruzzone "deshacernos de la OEA, del TIAR, de la Junta Interamericana de Defensa, en resumen, de todo el sistema interamericano de defensa elaborado por Estados Unidos desde el año 1948" (citado por Boron, 2013: 89). Los gobiernos latinoamericanos deberían renunciar a participar en ejercicios militares conjuntos con las fuerzas armadas de Estados Unidos, al tiempo que culminar la conformación de la CELAC y fortalecer su funcionamiento como una institución con capacidad de emitir políticas que comprometan su cumplimiento entre los Estados de la región. A las medidas añadidas por Bruzzone, Boron señala que enfrentar la dependencia armamentística respecto a Estados Unidos lleva a la necesidad de reemplazar el armamento de origen estadounidense por otro equivalente pero procedente de países con los cuales no exista una hipótesis de conflicto (Ibid.: 170).

Las declaraciones de América Latina como zona de paz podrían a su vez complementarse con políticas regionales conducentes a la moratoria en la importación de armas pequeñas y la adopción de estrictas medidas de uso por parte de personas particulares, incidiendo en la disminución de los niveles de posesión de armas, y aminorando una de las amenazas que mayores conflictos acarrea en las fronteras. La declaración de una zona de paz debería ser consistente con la disponibilidad de un stock de armamentos estrictamente indispensable cuyos parámetros deberían ser materia de un estudio específico. La carrera armamentista representa una amenaza mundial, tanto por sus efectos sociales como ambientales. Los únicos beneficiarios de este proceso son un puñado de grandes corporaciones y países que presionan a que recursos económicos que de otra forma podrían orientarse para solidificar procesos productivos o demandas sociales, se destinen para la destrucción. En el marco de las declaratorias de América Latina como zona de paz, esta región podría constituirse en un referente universal para impulsar una moratoria necesaria al armamentismo.

Una reflexión particular amerita el incremento en el gasto militar y el multifacético papel asignado a las Fuerzas Armadas en la región. Aún aceptando la necesidad de modernizar armamento obsoleto y garantizar la protección del patrimonio natural de los países latinoamericanos, el enfoque adoptado por los gobiernos latinoamericanos en relación al papel de las Fuerzas Armadas sugiere similitudes muy cercanas con el discurso hegemónico de Estados Unidos, el desplazamiento del concepto de defensa por el de seguridad nacional (Garzón, 2012), y el consecuente combate a las amenazas y riesgos provenientes de fuerzas nacionales e internacionales.

La centralidad que ha adquirido el concepto de seguridad ha dado paso, como lo señala Garzón (Ibid.) a que bajo su paraguas se aborden no solo los convencionales alcances de la defensa, sino que se enfrenten condiciones que se consideran pueden dar lugar a la inestabilidad social y a la alteración del orden democrático, abarcando desde el control del tráfico ilícito de drogas y armas, la violencia y la criminalidad, la construcción de obras emergentes, el apoyo ante los posibles efectos del cambio climático, hasta el cumplimiento de un papel de agente encargado de precautelar los recursos naturales estratégicos y las 
subsiguientes actividades de explotación, con el consiguiente control y contención de las expresiones de resistencia que pudieran surgir de las comunidades afectadas. En efecto, tras la ausencia de conflictos fronterizos y de ataques externos, las Fuerzas Armadas "se han ocupado de otras labores como una manera de justificar su existencia, ganar presupuesto y mantenerse activos" (Ibid.: 40).

El involucramiento de las Fuerzas Armadas en tareas ajenas a su naturaleza, coloca al discurso de defensa de la región en una posición sino contradictoria, al menos ambigua y poco clara con respecto a las decisiones que en materia de seguridad y defensa emanan desde Washington y el Pentágono. El nuevo papel asignado a las Fuerzas Armadas advierte, más bien, el apego a un discurso hegemónico en el campo militar construido por Estados Unidos y una limitada capacidad de los Estados de la región para marcar una senda distinta.

En este contexto, más que un distanciamiento total respecto a la política de defensa impuesta por Estados Unidos, la actual realidad sugiere que América Latina registra el surgimiento de una suerte de híbrido en el que la combinación de instrumentos de defensa y seguridad no solo que refuerzan el control y acceso a los recursos naturales, sino que han permitido justificar en gran parte y, pese a los tintes soberanistas y de autodeterminación que están presentes en los discursos y declaraciones oficiales, el mantenimiento de un alto gasto militar y la compra de armamento. Como se ha argumentado a lo largo de este documento, estas posturas, que de alguna manera prolongan viejas prácticas en torno a la defensa y la seguridad, se combinan con otras que dan cuenta de la existencia de posiciones que buscan reconfigurar modelos geopolíticos más autónomos en relación a lo que sucedió durante buena parte del siglo XX.

En la asignación de nuevas tareas a las Fuerzas Armadas, para las que sus contingentes no han sido formados, cabe al menos interrogar cómo actuarán los mecanismos de control ante un proceso de sobreexposición de las Fuerzas Armadas como el que parecería estar tomando lugar a raíz de los cambios adoptados en la región. Aunque no ejerzan el poder, los aparatos militares mantienen aún un fuerte peso en las sociedades latinoamericanas -una de las expresiones de la alta autonomía que aún mantienen es el nivel de gasto militar de la región-, lo que daría cuenta de nuevas formas de poder militar y de arreglos establecidos entre el poder civil y las Fuerzas Armadas que responden a las fallas de la institucionalidad de los Estados.

Ligado a lo anterior un segundo elemento que se propone es avanzar en una concepción de seguridad colectiva en varias áreas del planeta (como las zonas libres de armas nucleares) ${ }^{17}$. La seguridad colectiva no implica desconocer la integridad territorial de los Estados, sino acentuar una noción de soberanía distinta a la que ha predominado hasta hoy, fortaleciendo los entendimientos comunes, y los acuerdos regionales, no únicamente alrededor de temas comerciales, sino privilegiando el bienestar de la población, así como un mejor enfrentamiento a los temas ambientales y el manejo de bienes comunes que rebasan las fronteras o los límites entre los Estados.

Una propuesta de esta naturaleza tampoco pone en cuestión la existencia de fronteras,

\footnotetext{
${ }^{17}$ Esta noción difiere del "sistema de seguridad colectiva" en el Mar Caribe dirigido a "enfrentar la agresión cubana y soviética en esa parte del hemisferio occidental", promovida por el régimen terrorista implantado desde 1971 por Jean-Claude Duvalier (Baby Doc) en Haití y al represivo gobierno del terrateniente "socialdemócrata" dominicano Silvestre Guzmán Fernández (Suárez, 2006: 49).
} 
aunque sí relativiza el peso que han tenido históricamente debido a la pérdida de sus funciones tradicionales (a partir de la década del 2000 existe un consenso bastante extendido de que las fronteras dejaron de ser solo mecanismos de delimitación; tampoco son lugares en proceso de desaparición, ni son estructuras estáticas y permanentes y espacialmente localizables) (Lois, 2014), al tiempo que adecua los arreglos institucionales y políticos a la realidad contemporánea sujeta a procesos mundiales que no pueden ser controlados por un solo Estado.

Bajo la noción de seguridad colectiva el énfasis radicaría en la protección de las fronteras sub-continentales y no de las que separan a los países. Sobre estas últimas, merece la pena examinarse con profundo detenimiento diversas iniciativas que a nivel mundial y continental se han mostrado rutas viables en la solución de arreglos limítrofes $o$ controversias, como la creación del Parque Binacional El Cóndor que se constituyó tras la firma de los Acuerdos de Paz firmados entre Ecuador y Perú en 1998 o los distritos fronterizos conformados por parques nacionales entre las fronteras de Argentina y Chile ${ }^{18}$. Supone, también, regresar a ver con seriedad propuestas como la de las comunidades negras e indias del Pacífico colombiano por construir "comunidades o territorios de paz" y "territorios de protección" bajo el liderazgo de la Asociación Campesina Integral del Atrato (ACIA) y del Proceso de Comunidades Negras (PCN) (Escobar, 2005), o el espacio trinacional integrado por 57 municipios rurales de Bolivia, Chile y el Perú que constituyeron la Alianza Estratégica Aymaras Sin Fronteras como una respuesta a la falta de acción de los gobiernos centrales (Rouvière, 2009, citado por Benedetti, 2014). En este orden cabría también analizar las implicaciones de los acuerdos especiales para gestionar cuencas y represas hidroeléctricas compartidas como aquellos suscritos en el Cono Sur con la participación de Argentina, Uruguay, Brasil y Paraguay, y el turismo como una actividad orientada a resignificar las fronteras entre los Estados europeos. La intención, en este caso, era subvertir su carácter de periferias a fin de convertirlas en elementos centrales del proyecto comunitario (Lois, 2014). Cabría también debatir en torno a la propuesta de reconceptualizar el espacio territorial nacional como un "lugar de vivienda", según lo plantea Agnew (2008: 187) para hacer frente a un mundo colmado de flujos migratorios cuyo dinamismo es irreversible. Al asumir el espacio territorial nacional como un "lugar de vivienda" para las poblaciones asentadas en un territorio determinado, Agnew sostiene que nos alejaríamos de las narrativas nacionalistas que cultivan la creencia de que el territorio es una forma de propiedad. Dora Kostakopoulou (2006, citado por Ibid.: 187) profundiza esta mirada al proponer la vigencia de un "registro cívico" que contemple, como única condición para la residencia, demostrar la voluntad para vivir de acuerdo a reglas democráticas, el cumplimiento de algunos requerimientos formales y la ausencia de un historial delictivo serio.

El cambio de énfasis - de las fronteras internas a las externas-, no solo que actuaría en contra de la reproducción de los rasgos más perversos de la matriz liberal colonial de los Estados, sino que sería un paso inicial para contrarrestar los modelos de militarización y control de las fronteras entre los países. Hoy más que nunca, la historia reclama de una

\footnotetext{
${ }^{18}$ En la región patagónica, distribuida entre la Argentina y Chile, a partir de la década de 1920 para enfrentar las controversias alrededor de la circulación a ambos lados de la cordillera se crearon los parques nacionales de: Nahuel Huapi (1936), Lanín (1937) y Los Arrayanes (1971) del lado argentino; Vicente Pérez Rosales (1926); Villarica (1940) y Puyehue (1941) en el territorio chileno. Los parques nacionales se transformaron, virtualmente, en distritos fronterizos que ejercieron una función de "argentinización" y de "chilenización", respectivamente (Valverde, 2012, citado por Benedetti, 2014: 31).
} 
fuerte unidad y convergencia de los intereses de los países latinoamericanos como un medio para avanzar en una más firme articulación entre relaciones internacionales y espacio y como una poderosa herramienta para enfrentar la hegemonía militar que se nos pretende imponer, de la mano con un imaginario que estigmatiza a las fronteras y a su población.

Un tercer aspecto alrededor de las fronteras y estrechamente vinculado con una territorialidad colectiva en materia de seguridad es incidir en el cambio de énfasis del Proyecto Mesoamericano y la Iniciativa de Integración de la Infraestructura Regional de Sudamérica (IIRSA). En lugar de actuar como soportes para la exportación de commodities, en gran medida producidos por las grandes transnacionales de la minería, la madera, la celulosa y las plantaciones para combustibles, es necesario insistir en los requerimientos de los mercados locales, nacionales y regionales, en la importancia de la seguridad y soberanía alimentarias, en el mantenimiento de acervos históricos vinculados a la agrobiodiversidad, así como en la implementación de políticas democráticas y de justicia social para campesinos, pobladores rurales y pueblos indios, de forma paralela a la puesta en marcha de procesos productivos que antes que abonar en los graves problemas ambientales, se muestren a tono con las condiciones del entorno. Los impactos ambientales y sociales negativos asociados a los monocultivos extensivos o a la construcción de presas e hidroeléctricas de gran envergadura han demostrado que los beneficios económicos limitados a un puñado de empresas- no compensan de ninguna manera las grandes pérdidas sociales y los pasivos ambientales generados, de la misma manera que la producción para la exportación de materias primas ha evidenciado no ser una estrategia útil para salir de la "trampa" de la especialización que América Latina soporta por sus supuestas "ventajas comparativas".

En esta dirección podría pensarse en el impulso de proyectos que complementen y articulen las potencialidades de producción de la región, promoviendo la tradición productiva de las comunidades que viven a lo largo del área de intervención de estos proyectos. El Proyecto Mesoamericano y la IIRSA pueden ser una oportunidad para mejorar la vida de las poblaciones fronterizas si se lograra incorporar que "la experiencia del mundo muestra que hay muchas realidades no capitalistas, guiadas por la reciprocidad y el cooperativismo, a la espera de ser valoradas como el futuro dentro del presente", como lo afirma Boaventura de Sousa Santos en una reciente carta a las izquierdas.

El horizonte en el corto plazo lamentablemente no se dibuja alentador. La crisis económica que ha iniciado a impactar sobre América Latina, directamente provocada en muchos casos por intereses foráneos a la región (como la brusca bajada del precio del petróleo o el injusto acoso que se mantiene sobre Argentina alrededor de los fondos buitre), el desgaste político de varios gobiernos post neoliberales y en ocasiones, el retroceso y giro a la derecha de sus posturas iniciales bajo el escudo del "pragmatismo" o la eficiencia, el debilitamiento de organizaciones y movimientos sociales a las que se intentó tornar funcionales a gestiones gubernamentales particulares, el raquítico juego democrático de la mayoría de nuestras sociedades, son algunos de los severos escollos presentes y que podrían determinar, para el caso de las regiones fronterizas, la sobre posición de dos fronteras: una frontera extractiva fomentada por los Estados, y una frontera de mayor seguridad para contrarrestar las presiones externas que se perciben como amenazas a la soberanía, lo que lejos de contribuir a superar las dificultades y limitaciones existentes, significará una profundización de los complejos indicadores que soportan las regiones fronterizas. En efecto, de mantenerse la actual orientación de los dos más ambiciosos proyectos de construcción de infraestructura, lo más probable es que las regiones de frontera de América 
Latina estén expuestas a un doble reto: por un lado estarán sujetas a los cada vez mayores dispositivos de seguridad y consecuentemente a prácticas de fronterización que han complejizado la vida de las poblaciones ahí asentadas, con implicaciones no menos graves en lo concerniente a la pérdida de soberanía y a la supeditación de nuestros países (y de sus fronteras) a los dictámenes de seguridad delineados desde los centros de poder económicos y militares; por otro lado, soportarán el avance de la frontera extractiva cuyas consecuencias han demostrado una profunda violencia social, política y cultural y una alteración completa de las formas de vida pre-existentes.

El último elemento y no por eso el menos importante, alude al desafío en torno a cómo conjugar el respeto a otras formas de vida al mismo tiempo que se garantiza el mantenimiento de la soberanía territorial de los Estados. Atender esta tensión resulta de particular importancia en países cuya normativa garantiza derechos colectivos de pueblos ancestrales o plantea, como en el caso de Bolivia y Ecuador, la construcción de un Estado Plurinacional. Inspirada en la lucha de los pueblos indios, la plurinacionalidad representa una potente noción para transitar hacia nuevos paradigmas de organización territorial, de soberanía y de nación. Desde la plurinacionalidad, "el territorio nacional pasa a ser el marco geoespacial de unidad y de integridad que organiza las relaciones entre diferentes territorios geopolíticos y geoculturales" (Santos, 2010: 140); la soberanía se convierte en el factor que posibilita el autogobierno y autodeterminación de unidades geográficas cohesionadas por la identidad étnica y cultural y la nación en el contenedor de varias naciones culturales dentro del mismo espacio geopolítico. De hecho, como lo menciona Santos, no son las naciones y pueblos, "anteriores al Estado moderno, los que deben justificar su autonomía, sino el Estado el que debe justificar los límites que le impone en nombre del interés nacional" (Ibid.).

Sin desconocer los cambios acaecidos en los Estados de América Latina, los que podrían justificar que hoy, y no antes, se desarrollen estrategias orientadas a incorporar las áreas subalternizadas a la dinámica nacional, este renovado interés por las fronteras parecería no responder únicamente a las mayores capacidades institucionales de los países latinoamericanos. Pensar desde esta óptica significaría aceptar que el desarrollo es un proceso lineal, que tarda pero llega, minimizando la complejidad que está presente en cualquier decisión política. Tampoco parecería justificarse este creciente interés por las áreas subalternizadas únicamente desde el prisma de la necesidad de garantizar la soberanía de los Estados. Si este fuera el caso, sería deseable, al menos, mínimos procesos de diálogo, acuerdo y concertación con las poblaciones allí asentadas bajo el supuesto de que las "fronteras vivas" son la mayor garantía para la soberanía de un país -algo que lamentablemente no ha caracterizado la definición de las políticas fronterizas que siguen atadas a una concepción clásica según la cual el Estado y sus representantes (gobiernos) son la única fuente de construcción territorial.

En contraste con el "deber ser", la renovada irrupción del Estado en áreas subalternizadas ha significado la mayoría de las veces la emergencia de conflictos sociales que interpelan la imposición de modelos exógenos a las realidades locales, de conflictos ecológicos que cuestionan el distinto uso que se pretende dar a un territorio, de conflictos ecológico-distributivos ${ }^{19}$, finalmente, que evidencian que la distribución de los impactos

\footnotetext{
${ }^{19}$ Los conflictos ecológicos distributivos aluden al desigual acceso a los bienes y servicios de la naturaleza. Se originan por el uso creciente de materia y energía que presiona la ampliación de las fronteras extractivas (la expansión de la frontera del petróleo, de la palma, de los minerales, a nuevos territorios) (Martínez Alier 2002) y están ligados a los actuales patrones de producción y consumo,
} 
provocados por el crecimiento económico varía en función de los patrones de poder que existan sobre la naturaleza y sus recursos. De ahí que la explicación al creciente interés por asegurar la presencia estatal en áreas subalternizadas obedezca a un complejo entramado que sugiere la interacción de dos procesos. Un primer elemento está ligado a lo que podría calificarse como soberanía económica y la consiguiente necesidad de consolidar el territorio de los Estados a través de la incorporación de áreas fronterizas y otros territorios que disponen de una importante riqueza natural. Junto a la mayor capacidad de los Estados o a un aparentemente nuevo discurso sobre la soberanía, sobresale el avance de la frontera extractiva en función de una nueva fase de acumulación de capital que empuja ajustes espacio-temporales provechosos para el funcionamiento del sistema (Harvey, 2004; Svampa, 2011). En la concreción de estos nuevos ajustes espacio-tiempo resulta decisivo considerar la reproducción de la lógica de inserción de nuestras economías al mercado mundial, en la que se reservó para América Latina el rol de proveedor de las materias primas necesarias para soportar el crecimiento industrial de Europa, primero, y de los países industrializados de Occidente después. En este contexto no resulta extraño que frente a los argumentos utilizados para forzar la incorporación de territorios al espacio nacional único (progreso, distribución de la riqueza) se hagan visibles diversos paradigmas de formas de vida que al confrontar la validez de la vía de desarrollo y crecimiento económicos, han puesto simultáneamente en el centro del debate a las nociones de territorio y naturaleza (Svampa, 2011).

En tanto proveedora de recursos naturales e ingresos requeridos por el país, resulta necesario matizar el hecho de que la fragilidad social y económica de las fronteras obedezca al "abandono" del Estado y a la consiguiente falta de presencia institucional-afirmación recurrentemente citada al caracterizar la realidad de los territorios fronterizos (ver al respecto Ramón y Torres 2004; Lauret 2009; Espinoza 2008) - y proponer que las fronteras han tenido y tienen una presencia gubernamental que históricamente privilegió una lógica de explotación y aprovechamiento de los recursos naturales, en perjuicio de la atención de la población y la construcción de entornos favorables para la reproducción social y cultural. Cuando se trata de garantizar la operación de previos o nuevos procesos de acumulación, la presencia del Estado es indiscutible.

En lo sustantivo, la incorporación de las regiones fronterizas al territorio nacional -al Estado-nación- se ha dado, por tanto, en función de su papel como áreas proveedoras de los recursos naturales necesarios para promover el crecimiento y desarrollo del resto del país. Hacia futuro, lamentablemente, no se avizoran cambios sustantivos en el papel asignado a las fronteras. Por el contrario, su inserción a la lógica de desarrollo del país como áreas proveedoras de recursos podría agudizarse en función del enfoque que adopten las inversiones y las decisiones de seguridad en el marco de los proyectos de integración de infraestructura, así como a consideraciones geopolíticas vinculadas con el interés estratégico de Estados Unidos por fortalecer el control de la riqueza natural que dispone América Latina.

Ligado a la apropiación de la riqueza natural de las fronteras, un segundo elemento en torno al renovado interés por incorporar las áreas fronterizas tiene que ver con la consolidación de los espacios estatales y el complejo proceso de construcción de la nación,

especialmente dilapidadores en el Norte, que inciden de manera directa en el aumento de la conflictividad local y global provocada por el acceso a los recursos naturales, los impactos de la contaminación y los problemas asociados a la disposición de desechos. Implican, por tanto, la confrontación de distintos intereses: entre quienes perciben a la naturaleza solo como un recurso productivo más, como capital, y quienes aprecian que la naturaleza es sobre todo el soporte de vida. 
no solo en torno a las políticas de delimitación y clasificación típicas de las fronteras, sino también de aquellas políticas de representación y de identidad que guardan relación con paisajes discursivos/emocionales de poder sustentados en algún tipo de nacionalismo. En la práctica, estas políticas se reflejan en la conversión de las fronteras en espacios de creciente control y vigilancia y en la constante construcción y recreación de discursos y prácticas sobre lo nacional. Mediante la mayor securitización es posible contribuir a la consolidación del espacio estatal tanto por el fortalecimiento de los límites de una sociedad particular, cuanto por el conjunto de procedimientos que facilitan el establecimiento de distinciones sociales, culturales y políticas entre grupos humanos. En la construcción del discurso y de las expresiones de nacionalismo intervienen variados elementos: el incremento de la migración y el desplazamiento mundial de poblaciones; los cambios introducidos en los países de la región sobre todo aquellos vinculados con la consecución de mejores indicadores sociales, la identidad nacional como premisa de la constitución del Estadonación (Newman y Paasi, 1998) o la presencia de movimientos nacionalistas y miles de culturas, entre las que florecen (o pueden florecer) preocupaciones sobre la identidad social y territorial (Rapaport, 1996, citado por Ibid.: 197-198).

La recreación de discursos sobre lo nacional, la afirmación de una visión de soberanía estrechamente atada al territorio y la exaltación del nacionalismo están presentes en varios de los mandatarios del período post-neoliberal a partir de mediados de la primera década de este siglo. "Patria altiva y soberana", la "Patria ha vuelto" o la "Patria ya es de todos" dice Rafael Correa en Ecuador de manera similar al "Hemos recuperado la Patria" que expresa Evo Morales en Bolivia. En Argentina Cristina Kischner advertía que "mientras haya un pobre en la Patria no habrá victoria definitiva" o levanta como consigna hacia sus críticos "hemos reconstruido la Patria"; Hugo Chávez apelaba a "la unión de una gran hermandad nacional" y al orgullo de ser venezolanos como el factor que impulsará "la grandeza de la Patria", exhortaba poner delante "la gran pasión: la Patria, el interés de la nación" y a luchar por una "Patria soberana". Frente a este resurgir nacionalista cabe recordar que los discursos y prácticas en torno a lo nacional frecuentemente están orientados a consolidar la territorialidad, la seguridad, las identidades, emociones, memoria y el eje pasado-presente-futuro (Johnson, et al., 2011), desde una sola mirada, generalmente atada al discurso hegemónico. En este retorno a lo nacional, no todos los sectores sociales están incluidos de la misma manera. Otras formas de vida y organización, distintas a las que están presentes dentro de la concepción de "Patria" y de la visión hegemónica tienden a ser colonizadas a través de la utilización de diversos medios: el despojo violento y la consiguiente acumulación por desposesión, la imposición de narrativas hegemónicas en torno al territorio, la etnicidad y la nación; la implantación de una única visión del mundo o la homogenización interna.

Quienes defienden planteamientos nacionalistas, aunque lo hagan bajo una supuesta defensa de la soberanía y digan rechazar la injerencia externa, reproducen una cierta forma de imperialismo, como sostiene Porto-Gonçalves (2006). Convencidos, como están, de que su papel es garantizar el progreso de la nación, hacen caso omiso de las diferencias culturales y reúnen bajo un solo Estado territorial a diversos lugares. El centro o capital conforma, así, un contenedor de poder que se sostiene a través de bloques históricoregionales-que proyectan, al interior de las unidades territoriales nacionales, las mismas relaciones asimétricas coloniales que constituyeron a los Estado-nación (Ibid.).

La conjunción en el concepto de Estado-nación del espacio-tiempo donde se juntan la comunidad, la cultura y el mapa territorial, o en otras palabras, la congruencia entre gente, 
historia y territorio es, como advierte e intelectual indú Shiv Visvanathan (2007) fácil a nivel de definición, pero problemática en la realidad. En lugar de ser una categoría abierta, la nación se torna en un proceso de exclusión en el que la fuerza con la que se intenta construir la homogeneidad termina por relegar y discriminar a pueblos portadores de otras visiones y prácticas culturales como son los pueblos indios o los grupos étnicos ancestrales quienes deciden vivir en aislamiento voluntario.

Tomando en cuenta que las fronteras son un constructo social, la geografía crítica señala la necesidad de poner atención en las prácticas de fronterización y en las cuestiones ligadas a la identidad y el poder. Esto se torna particularmente importante en momentos en que las nociones de territorialidad y fronteras están vinculadas a las reivindicaciones de varios grupos sociales para definir y redefinir las relaciones entre lo social y el espacio físico (Newman y Paasi, 1998), y es todavía más elocuente en un contexto como el latinoamericano que tiene por delante el desafío de construir y dar cabida a la plurinacionalidad. La continuidad y profundización de una visión de seguridad sobre los territorios fronterizos, su transformación en espacios donde surgirán enclaves productivos o de comercio, la colonización y asimilación forzada de las poblaciones fronterizas a una dinámica que les es adversa, pueden en el corto plazo actuar como un espejismo respecto a la supuesta modernización de los países, a la integración nacional dentro de un solo espacio político único o al fortalecimiento de la soberanía. Como en todo espejismo, tarde o temprano la realidad se manifestará con toda su crudeza. La aplicación de propuestas de integración parciales, estrechamente supeditadas a la esfera económica, los crecientes flujos comerciales, la profundización de actividades primario-exportadoras, la escasez de oportunidades de empleo para las poblaciones que viven en regiones fronterizas, la pérdida de sus medios de vida, trastornarán las relaciones entre los Estados y harán de la gobernabilidad un fenómeno más complejo, atravesado por regímenes legales que podrían sobrepasar la soberanía de los territorios (Brunet-Jailly, 2011), lo que a su vez tiene repercusiones sobre la equidad y la justicia social y ambiental, manteniendo, cuando no ahondando, las difíciles condiciones de vida de las poblaciones ubicadas en áreas fronterizas.

El peso asignado a la integración comercial y económica significará para los pueblos indios asentados en las regiones fronterizas de América Latina una abierta amenaza a su sobrevivencia cultural, redituando las prácticas discriminatorias y la implementación de políticas de segregación, en ocasiones, explícitamente racistas, presentes durante la conformación de los Estados en América Latina (Newman y Paasi, 1998). En el renovado interés por las áreas subalternizadas y por las fronteras se siguen reproduciendo modelos de colonialidad que pueden acabar con la continuidad histórica de pueblos indios asentados en estas áreas al presionar sobre sus territorios, fortalecer el despojo de sus medios de vida e insertarlos de manera violenta en relaciones sociales y económicas que les son desconocidas. La combinación de integración económica y seguridad que ha sido privilegiada para el abordaje de las fronteras, terminará subsumiendo a comunidades y pueblos no enteramente incrustados en la dinámica capitalista y a los bienes comunes que allí se encuentran, a los circuitos que dan vida al capital, desconociendo que la sobrevivencia de los pueblos indios dependerá en gran parte, como lo señala Díaz Polanco, de la garantía de acceso y usufructo a su territorio como base de sustentación material y espiritual y como fundamento de su organización socio-étnica, así como de la "ampliación de la territorialidad - en condiciones nuevas, incluso la actualización de antiguas territorialidades regionales, aunque no necesariamente los mismos territorios anteriores" (1997: 30).

Dentro del nuevo regionalismo, el abordaje de las fronteras no ha podido escapar de 
los patrones diseñados por la matriz capitalista neoliberal dominante que ha presionado para modificar la visión convencional de la territorialidad y facilitar el funcionamiento de esquemas macro-regionales de fronteras como la Unión Europea (proyecto de integración que se forjó entre 1970 e inicios de 1980), el Tratado de Libre Comercio de América del Norte (NAFTA, por sus siglas en inglés) o MERCOSUR (Anderson y O’Dowd, 1999), que dejan una limitada capacidad de autonomía y autodeterminación a los países. A manera de ejemplo cabe citar la reorganización y distribución territorial que toma actualmente lugar en función de satisfacer la demanda de agrocombustibles. La ocupación de áreas del biocorredor del Chocó para el cultivo de palma africana, con Colombia ocupando un puesto central en esta dinámica que se desparrama hacia Ecuador por el sur y Venezuela al norte, advierte la configuración de un eje para la producción de agrocombustibles derivados de la palma africana que se consolida independientemente de la presencia, en cada uno de estos países, de gobiernos con posiciones políticas diversas y aparentemente opuestas. Ejes similares de producción de agrocombustibles serían los de etanol, liderado por Brasil para extenderse, desde este territorio a Centro América y el Caribe; y, el de soja transgénica que, con Argentina a la cabeza, se difunde a través de Brasil, Bolivia y Paraguay.

En ausencia de una postura regional frente a las fronteras y del predominio de una lógica de seguridad, la consecuencia ha sido alentar a que los Estados desarrollen medidas unilaterales, sustentadas en lecturas superficiales de la realidad fronteriza y favoreciendo únicamente el control, como medio más cercano para hacer frente a situaciones que en ocasiones parecerían desbordarse. En el mejor de los casos, los países de la región han puesto en marcha acuerdos bilaterales para impulsar zonas de integración de dudosa eficacia cuyo examen más detenido debería ser la base para fundamentar la formulación de nuevas políticas fronterizas.

El ejercicio de un regionalismo renovado en América Latina, junto a la mayor importancia concedida a la integración y la articulación de intereses colectivos representan oportunidades excepcionales para concretar procesos de discusión y ejecución de prácticas de frontera que superen el dominio exclusivo de lo público y que incorporen la palabra y las necesidades de la gente. No obstante, parecería ser que este regionalismo renovado enfrentaría algunas limitaciones actuales como para satisfacer tal premisa. Sin el ánimo de realizar una evaluación profunda de los cambios suscitados en los últimos dos o tres años, lo que rebasa el alcance de este texto, es necesario tomar en cuenta retrocesos y problemas que se han suscitado en el escenario político latinoamericano reciente. La erosión que soporta el capitalismo como sistema mundial podría determinar una mayor injerencia de Estados Unidos sobre nuestras economías, estimulando el agravamiento del equilibrio inestable que pone en juego la continuidad y profundización de los cambios emprendidos por los gobiernos pos neoliberales, o su retroceso en manos de la derecha. Tal inestabilidad no es sin embargo motivada únicamente por elementos externos ni puede ser solo endosable a las fuerzas de derecha presentes al interior de nuestros países. Existen también variables adicionales que han erosionado y debilitado procesos políticos prometedores de cambios sustanciales que han distanciado a los gobiernos "del cambio" de sus aliados iniciales y de los postulados que los llevaron al poder.

Las organizaciones regionales que organizan los territorios supranacionales como la Unión de Naciones Sudamericanas (UNASUR) o aquellas que pueden incidir en la definición de políticas relativas al territorio como CELAC y ALBA-TCP, son relevantes a la hora de pensar la dinámica fronteriza y superar la forma en cómo las fronteras han sido tradicionalmente tratadas: oscilando entre el abandono a la imposición de modelos y 
prácticas exógenas con rasgos coloniales, casi siempre matizados de estrategias de seguridad y criminalización a la población fronteriza. Sin embargo, a la luz de las limitaciones actuales, el giro conservador en curso podría incluso agudizarse y con él, verificar un mayor empobrecimiento de posturas democráticas. La caída en el precio del petróleo y demás materias primas podría significar retrocesos en términos del discurso nacionalista y aún disminución del entusiasmo con el que se ha empujado la inversión pública, fortaleciendo más bien políticas de claro corte conservador que poco han aportado a la superación de la matriz de colonialidad que atraviesa a las sociedades latinoamericanas.

Ante este panorama y aunque el cómo y por dónde aún no estén claros serán, como siempre lo ha sido en la historia, los pueblos y sus organizaciones, los que retomen y fuercen los cambios, las necesarias transformaciones democráticas y de justicia social y ambiental y la construcción de nuevos horizontes. Para quienes habitan en áreas fronterizas, las fronteras son parte de su vida cotidiana y constituyen una de sus principales estrategia de sobrevivencia. Valdría la pena aprender de estos pobladores, que en lugar de enaltecer las diferencias, han construido formas organizativas y relaciones comunitarias sustentadas en el valor concedido a los aspectos unificadores con los "otros". Esto implicaría otorgar a lo local la importancia que amerita, revertir la centralidad asignada a las dinámicas globales, al comercio, la competencia o la integración económica en función de los requerimientos mundiales de la acumulación y re-significar que "es nuestra inevitable inmersión en el lugar -y no lo absoluto del espacio- la que tiene prioridad ontológica en la generación de la vida y de lo real" (Casey 1996: 18 citado por Escobar, 2005: 161). La construcción de una mirada renovada sobre las fronteras requiere romper con el viejo paradigma del Estado-nación con base territorial. Mientras esto no suceda, la seguridad, el control, la clasificación de personas y cosas, o la persecución del otro seguirán siendo la premisa en las políticas fronterizas. 


\section{Bibliografía}

Albuquerque, José Lindomar (2014). Fronteiras: entre os caminhos da observação e os labirintos da interpretação. En: Cardin, Eric Gustavo y Silvio Antônio Colognese (org.): As Ciências Sociais nas Fronteiras. Teorias e metodologias de pesquisa. Cascavel: Gráfica JB, p. 61-80.

Agnew, John (2008). Borders on the mind: re-framing border thinking. Ethics \& Global Politics. Vol. 1(4): p. 175-191.

Alimonda, Héctor (2011). La colonialidad de la naturaleza. Una aproximación a la Ecología Política latinoamericana. En: Alimonda, Héctor (coord.) La naturaleza colonizada. Ecología política y minería en América Latina. CLACSO (Consejo Latinoamericano de Ciencias Sociales). Buenos Aires: Ediciones CICCUS, p. 21-60.

Amoore, Louise (2006). Biometric borders: Governing mobilities in the war on terror, Political Geography. (25): p. 336-351.

Anderson, James y Liam O'Dowd (1999). Borders, border regions and territoriality: contradictory meanings, changing significance. Regional Studies. Journal of the Regional Studies. 33(2): p. 593-604.

Báez Landa, Mariano (2010). De indígenas a campesinos. Miradas antropológicas de un quiebre paradigmático. Revista do Centro de Estudos Rurais (RURIS). 2(3): p. 55-74.

Benedetti, Alejandro (2014). Espacios fronterizos del sur sudamericano. Propuesta de un modelo conceptual para su estudio. Estudios Fronterizos. 15(29): p. 11-47.

Bernecker, Walther L. (2004). Fronteras estatales, dinamismo continental. La relatividad de las fronteras en Iberoamérica. Iberoamericana. 4(16): p. 71-86.

Bonilla, Omar (2010). "The Manta-Manaos project: nature, capital and plunder". s/l.: Acción Ecológica.

Boron, Atilio (2013). América Latina en la Geopolítica del Imperialismo. Argentina: Ediciones Luxemburg.

Brunet-Jailly, Emmanuel (2011). Borders, Borderlands and Theory: An Introduction. Geopolitics. (16): p. 1-6.

Cardin, Eric Gustavo (2014). Teoría das fronteiras e totalidade. En: Cardin, Eric Gustavo y Silvio Antônio Colognese (org.): As Ciências Sociais nas Fronteiras. Teorias e metodologias de pesquisa. Cascavel: Gráfica JB, p. 43-59.

CDS (2010) "Procedimientos de aplicación de las medidas de fomento de la confianza y seguridad". Consejo de Defensa Suramericano-UNASUR. Disponible en: http://www.unasursg.org. Consulta realizada el 02/11/2014

CDS. (2012). "Registro Suramericano de Gasto de Defensa. Avance Preliminar. Resumen Ejecutivo". Quito: Consejo de Defensa Suramericano-Secretaría General de UNASUR. Disponible en: http://www.unasursg.org. Consulta realizada el 02/11/2014

Ceceña, Ana Esther (2013). La dominación de espectro completo sobre América. Revista Patria. Análisis políticos de la defensa. Dossier Vigilancia Global. Quito: Ministerio de Defensa Nacional. (1): p. 43-59.

Ceceña, Ana Esther, Paula Aguilar y Carlos Motto. (2007). Territorialidad de la dominación. Integración de la Infraestructura Regional Suramericana (IIRSA). Buenos Aires: Observatorio Latinoamericano de Geopolítica.

CEPAL (2013). Estudio económico de América Latina y El Caribe. Tres décadas de crecimiento desigual e inestable. Comisión Económica para América Latina y el Caribe. Disponible http://www10.iadb.org/intal/intalcdi/PE/2013/12522es.pdf. Consulta realizada el 23/01/2015

Chemillier-Gendreau, Monique (2013). La difícil conquista del mar. En: El Atlas de los conflictos de fronteras de Le Monde Diplomatique. Madrid: Fundación Mondiplo. 
UNED (Universidad de Educación a Distancia), p. 13-19

Delgado Ramos, Gian Carlo (2001). El futuro de la Amazonía. Questão Ambiental Latinoamericana, 74A-87A.

Díaz-Polanco, Héctor (1997). La rebelión zapatista y la autonomía. Primera edición. México: Siglo XXI Editores.

Escobar, Arturo (2005). Más allá del Tercer Mundo. Globalización y Diferencia. Bogotá: Instituto Colombiano de Antropología e Historia. Universidad del Cauca.

García Pérez, Juan. (2005). Conflictos territoriales y luchas fronterizas en América Latina durante los siglos XIX y XX. Norba. Revista de Historia. (18): p. 215-241.

García Pinzón, Viviana. (2014). En los confines del Estado. Una mirada comparada a la seguridad en las zonas fronterizas de Sudamérica. En: Zavaleta, José Alfredo (comp.) El laberinto de la inseguridad ciudadana: bandas criminales, seguridad de fronteras y regímenes penitenciarios en América Latina. Buenos Aires: CLACSO (Consejo Latinoamericano de Ciencias Sociales), p. 227-256.

Garzón Vergara, Juan Carlos (2012). La seguridad y las Fuerzas Armadas en América Latina y El Caribe. Nuevos desafíos para la construcción de una democracia. En: Velozo, Álvarez et al. El papel de las Fuerzas Armadas en América Latina: seguridad interna y democracia. Buenos Aires: CLACSO (Consejo Latinoamericano de Ciencias Sociales), p. 12-62.

Grimson, Alejandro (2005a). Fronteras e identificaciones nacionales: diálogos desde el Cono Sur. Iberoamericana. V(17): p. 91-99.

Grimson, Alejandro (2005b). Fronteras, estados e identificaciones en el Cono Sur. En: Mato, Daniel (comp.) Cultura, política y sociedad. Perspectivas Latinoamericanas. Buenos Aires: Consejo Latinoamericano de Ciencias Sociales (CLACSO): s.n.

Harvey, David. (2004). El "nuevo" imperialismo: acumulación por desposesión. Socialist Register. No. 40: p. 99-129.

Isacson, Adam, Lisa Haugaard, Abigail Poe, et al. (2013). Hora de escuchar: tendencias en asistencia de seguridad de los Estados Unidos hacia América Latina y el Caribe. Latin American Working Group Education Fund. Center for International Policy. WOLA (Washington Office on Latin America). Disponible en: http://www.wola.org/wola_publications. Consulta realizada el 03/09/2014

Johnson, Corey et al. (2011) Interventions on rethinking 'the border' in border studies. Political Geography. 30: p. 61-69.

Latouche, Serge (2014). Limite. Ciudad Autónoma de Buenos Aires: Adriana Hidalgo editora.

Lois, María (2014). Apuntes sobre los márgenes: fronteras, fronterizaciones, órdenes socioterritoriales. En: Cardin, Eric y Silvio Antônio Colognese (org.) As Ciências Sociais nas Fronteiras. Teorias e metodologias de pesquisa. Cascavel: Gráfica JB, p. 239-261.

Machado Aráuz, Horacio (2010). Minería transnacional y neocolonialismo. Cuerpos y territorios en las disputas coloniales de nuestro tiempo. En: Resistencias populares a la recolonización del continente. Buenos Aires: Ediciones América Libre, p. 303-341.

Martínez Alier, Joan (2002). The Environmentalism of the Poor. A Study of Ecological Conflicts and Valuation. Cheltenham: Edward Elgar Publishing.

Mbembe, Achille (2008). Al borde del mundo. Fronteras, territorialidad y soberanía. En: Estudios poscoloniales. Ensayos fundamentales. Madrid: Queimada Gráficas, p. 167195.

Navarro Floria, Pedro (2011). Territorios marginales: los desiertos inventados latinoamericanos. Representaciones controvertidas, fragmentadas y resignificadas. En: Trejo Barajas, Dení Los desiertos en la historia de América. Una mirada 
multidisciplinaria. México: Universidad Michoacaba de San Nicolás Hidalgo y Universidad Autónoma de Coahuila, p. 208-228.

Newman, David y Anssi Paasi (1998). Fence and neighbours in the postmodern world: boundary narratives in political geography. Progress in human geography. (22)2: p. 186-207

Porto-Gonçalves, Carlos Walter (2006). A reinvenção dos territórios: a experiência latinoamericana e caribenha. En: Ceceña, Ana Esther (coord.) Los desafíos de las emancipaciones en un contexto militarizado. Buenos Aires: CLACSO (Consejo Latinoamericano de Ciencias Sociales), p. 151-197

Porto-Gonçalves, Carlos Walter (2004). El desafío ambiental. s.1.: PNUMA.

Quijano, Aníbal (2000). Colonialidad del poder, eurocentrismo y América Latina. En: Lander, Edgardo (comp.) La colonialidad del saber: eurocentrismo y ciencias sociales. Perspectivas Latinoamericanas. Buenos Aires: CLACSO (Consejo Latinoamericano de Ciencias Sociales).

Santos, Boaventura de Sousa (2010). Refundación del Estado en América Latina. Perspectivas desde una epistemología del Sur. Quito: Abya Yala. Universidad Politécnica Saleciana.

Saxe-Fernández, John (2009). América Latina: ¿Reserva estratégica de Estados Unidos?. Debates. X(25): 19-25.

Schallenberger, Erneldo (2014). Ruptura histórica e (des)continuidades culturais na fronteira: os desafios do pesquisador. En: Cardin, Eric y Silvio Antônio Colognese (org.) As Ciências Sociais nas Fronteiras. Teorias e metodologias de pesquisa. Cascavel: Gráfica JB, p. 215-237.

Shiva, Vandana (1995). Globalism, biodiversity and the Third World. En: Goldsmith, Edward, et al. The future of progress. Reflections on Environment and Development. Bristol: International Society for Ecology and Culture, p. 50-67.

Stedile, João Pedro (2013). Tendências do capital na agricultura. A questão agraria. (7): p. 19-3.

Suárez, Luis (2003). Madre América. Un siglo de violencia y dolor (1898-1998). La Habana: Editorial Ciencias Sociales.

Suárez, Luis. (2006). "Las agresiones de Estados Unidos contra América Latina y el Caribe: fuente constante del terrorismo de Estado en el hemisferio occidental". La Habana.

Suárez, Luis. (2014). "Estados Unidos vs. Nuestra América 20 años después del Tratado de Libre Comercio de América del Norte". La Habana.

Svampa, Maristella (2011). "Extractivismo neodesarrollista y movimientos sociales: ¿Un giro ecoterritorial hacia nuevas alternativas?". Quito: Fundación Rosa Luxemburgo.

UNASUR. (2008). "Estatuto del Consejo de Defensa Suramericano de la UNASUR". Santiago de Chile: Secretaría General de UNASUR. Disponible en http://www.unasursg.org. Consulta realizada el 02/11/2014

UNASUR (2014). "Tratado Constitutivo de la Unión de Naciones Latinoamericanas". Quito: Secretaría General de UNASUR. Disponible: http://www.unasursg.org. Consulta realizada el 02/11/2014

UNASUR-COSIPLAN (2011). Agenda de proyectos prioritarios de integración. s.1.: Consejo Suramericano de Infraestructura y Planeamiento. s/l.

UNASUR-COSIPLAN (2013). Cartera de proyectos 2013. IV Reunión de Ministros del COSIPLAN. Chile.

UNASUR-COSIPLAN (2014). Cartera de proyectos 2014. V Reunión Ordinaria del COSIPLAN. Montevideo.

Van Klaveren, Alberto (1983). El Lugar de Estados Unidos en la Política Exterior Latinoamericana. En Teoría y Practica de la política exterior Latinoamericana. 
Bogotá: FESCOL, p. 119 - 141.

Visvanathan, Shiv (2007). Interrogating the nation. Economic and political Weekly. 38(23): 2295-2302

Wilson, Japhy, Manuel Bayón y Henar Díez (2015). "Posneoliberalismo y urbanización planetaria en la Amazonía ecuatoriana". Quito: Instituto de Altos Estudios Nacionales y Centro Nacional de Estrategia para el Territorio.

\section{Otros documentos y páginas web consultados}

ALBA-TCP. "Construyendo un mundo pluripolar. Cumbres 2004-2013. Alianza Bolivariana para los pueblos de Nuestra América-Tratado de Comercio de los Pueblos (2013)". Disponible en: http://albatcp.org/public/documents/pdf/CumbresALBADic2004Dic2013.pdf. Consulta realizada el 06/11/2014.

ALBA-TCP. "Informe de Gestión 2004-2014. 10 años consolidando la solidaridad e integración entre los pueblos". Alianza Bolivariana para los pueblos de Nuestra AméricaTratado de Comercio de los Pueblos. Disponible en: <http://albatcp.org/public/documents/pdf/CumbresALBADic2004Dic2013.pdf $>$ Consulta realizada 08/11/2014.

Banco

Mundial.

$<$ http://datos.bancomundial.org/indicador/MS.MIL.TOTL.P1?display=default $>$

CELAC. "Declaración de La Habana". II Cumbre de la CELAC. 2014.

CELAC. "Declaración de Santiago". I Cumbre de la CELAC. 2013.

CELAC. "Declaración especial sobre desarme nuclear". La Habana, 2014.

CELAC. "Declaración especial de apoyo a la lucha contra el terrorismo en todas sus formas y manifestaciones". La Habana, 2014.

CELAC. "Declaración especial sobre el fortalecimiento de la integración". La Habana, 2014.

CELAC. Declaración especial sobre el tráfico ilícito de armas pequeñas y ligeras en todos sus aspectos en América Latina y el Caribe. La Habana, 2014.

CELAC. Declaración especial sobre la regularización migratoria como un mecanismo para lograr el ejercicio pleno de los derechos de las personas migrantes y sus familiares de los países miembros de la CELAC y el fortalecimiento de la integración regional. La Habana, 2014.

CELAC. "Plan de acción de la CELAC 2014". La Habana, 2014.

CELAC. "Proclama de América Latina y el Caribe como Zona de Paz". La Habana, 2014.

MERCOSUR. "Acuerdo sobre residencia para nacionales de los Estados Partes del MERCOSUR, Bolivia y Chile”. Brasilia, 2002.

UNASUR. "Acta de la Reunión Extraordinaria de Ministros de Relaciones Exteriores y Defensa de UNASUR". Quito, 2009.

UNASUR. "Acta de la Reunión Extraordinaria del Consejo de Defensa Suramericano". Santa Cruz, 2010.

UNASUR. "Acta de la VII Reunión Ordinaria de la Instancia Ejecutiva del Consejo de Defensa Suramericano". Lima, 2013.

UNASUR. "Acta. IX Reunión de la instancia ejecutiva del Consejo de Defensa Suramericano". Paramaribo, 2014.

UNASUR. "Declaración sobre Suramérica como zona de Paz". Lima.

UNASUR. "Declaración final. Primera Reunión de Ministras y Ministros de Defensa del Consejo de Defensa Sudamericano (CDS) de la UNASUR”. Santiago de Chile, 2009.

UNASUR. "Estatuto del Consejo Suramericano en materia de seguridad ciudadana, justicia y coordinación de acciones contra la delincuencia organizada transnacional". Salvador de 
Bahía, 2014

UNASUR. "Plan de Acción 2010-2011. Informe final. Diseño de una metodología común de mediación de gastos de defensa". La Paz, 2012.

UNASUR/CJEG/DECISIÓN/Nº10/2012, relativa a la aprobación del Estatuto del Centro de Estudios Estratégicos de Defensa, en el ámbito del Centro de Estudios Estratégicos de Defensa.

UNASUR/CMRE/RESOLUCIÓN N 19/2012, para fortalecer la cooperación en materia de seguridad ciudadana, justicia y coordinación de acciones contra la delincuencia organizada transnacional. 